Chapman University

Chapman University Digital Commons

$11-21-2019$

\title{
A Systematic Comparison of Lipopolymers for siRNA Delivery to Multiple Breast Cancer Cell Lines: In vitro studies
}

\author{
Hamidreza Montazeri Aliabadi \\ Remant Bahadur KC \\ Emira Bousoik \\ Ashley Barbarino \\ Bindu Thapa
}

See next page for additional authors

Follow this and additional works at: https://digitalcommons.chapman.edu/pharmacy_articles

Part of the Amino Acids, Peptides, and Proteins Commons, Biological Phenomena, Cell Phenomena, and Immunity Commons, Cancer Biology Commons, Chemical and Pharmacologic Phenomena Commons, Genetic Phenomena Commons, Genetic Processes Commons, Medical Genetics Commons, Medicinal and Pharmaceutical Chemistry Commons, Nucleic Acids, Nucleotides, and Nucleosides Commons, Oncology Commons, Other Chemicals and Drugs Commons, Other Pharmacy and Pharmaceutical Sciences Commons, and the Pharmaceutics and Drug Design Commons 


\section{A Systematic Comparison of Lipopolymers for siRNA Delivery to Multiple Breast Cancer Cell Lines: In vitro studies}

\section{Comments}

NOTICE: this is the author's version of a work that was accepted for publication in Acta Biomaterialia. Changes resulting from the publishing process, such as peer review, editing, corrections, structural formatting, and other quality control mechanisms may not be reflected in this document. Changes may have been made to this work since it was submitted for publication. A definitive version was subsequently published in Acta Biomaterialia, volume 102, in 2020. https://doi.org/10.1016/j.actbio.2019.11.036

The Creative Commons license below applies only to this version of the article.

\section{Creative Commons License}

\section{(c) (†) $\Theta$}

This work is licensed under a Creative Commons Attribution-Noncommercial-No Derivative Works 4.0 License.

\section{Copyright}

Elsevier

\section{Authors}

Hamidreza Montazeri Aliabadi, Remant Bahadur KC, Emira Bousoik, Ashley Barbarino, Bindu Thapa, Melissa Coyle, Parvin Mahdipoor, and Hasan Uludağ 
1

\title{
A Systematic Comparison of Lipopolymers for siRNA Delivery to Multiple Breast Cancer Cell Lines: In vitro studies
}

\author{
Hamidreza Montazeri Aliabadi ${ }^{1,3, *}$, Remant Bahadur K.C. ${ }^{2}$, Emira Bousoik $^{1}$, \\ Ashley Barbarino ${ }^{1}$, Bindu Thapa ${ }^{2}$, Melissa Coyle ${ }^{1}$, \\ Parvin Mahdipoor ${ }^{1}$, Hasan Uludağ $\breve{g}^{2,4,5, *}$
}

1 Department of Biomedical and Pharmaceutical Sciences, Chapman University School of Pharmacy, Harry and Diane Rinker Health Science Campus, Irvine, California 92618, United States

2 Department of Chemical and Material Engineering, University of Alberta, Edmonton, AB T6G 2V4, Canada

3 Center for Targeted Drug Delivery, Chapman University School of Pharmacy, Harry and Diane Rinker Health Science Campus, Irvine, California 92618, United States

4 Faculty of Pharmacy and Pharmaceutical Sciences, University of Alberta, Edmonton, AB, Canada, T6G 2E1

5 Department of Biomedical Engineering, Faculty of Medicine and Dentistry, University of Alberta, Edmonton, AB, Canada, T6G 2R3

\section{*Corresponding Authors:}

Hasan Uludağ, Ph.D.

\#2-020 RTF, Chemical \& Materials Engineering Department, Faculty of Engineering, University of Alberta, Edmonton, Alberta, Canada T6G 2G6.

Tel: (780) 492-0344. Fax: (780) 492-2881. E-mail: huludag@ualberta.ca

Hamidreza Montazeri Aliabadi, Pharm. D., Ph. D.

Department of Biomedical and Pharmaceutical Sciences, Chapman University School of Pharmacy, Harry and Diane Rinker Health Science Campus \#211, 9401 Jeronimo Road Irvine, CA 92618, USA Tel: (714) 516-5492. Fax: (714) 516-5481. E-mail: montazer@chapman.edu 


\begin{abstract}
The small interfering RNA (siRNA) therapy is a promising approach for treatment of a wide range of cancers, including breast cancers that display variable phenotypic features. To explore the general utility of siRNA therapy to control aberrant expression of genes in breast cancer, we conducted a detailed analysis of siRNA delivery and silencing response in vitro in 6 separate breast cancer cell models (MDA-MB-231, MDA-MB-231-KRas-CRM, MCF-7, AU565, MDAMB-435 and MDA-MB-468 cells). Using lipopolymers for siRNA complexation and delivery, we found a large variation in siRNA delivery efficiency depending on the specific lipopolymer used for siRNA complexation and delivery. Some lipopolymers were effective in all cell types used in this study, indicating the possibility of universal carriers for siRNA therapy. The delivery efficiency for effective lipopolymers was not correlated with dextran uptake in all cells tested, which indicated a receptor-mediated internalization for siRNA complexes with lipopolymers, unlike fluid-phase transfer associated with dextran uptake. Consistent with this, specific inhibitors involved in clathrin- and caveolin-mediated endocytosis significantly $(>50 \%)$ reduced the internalization of siRNA complexes in all cell types. Using JAK2 and STAT3 silencing in MDA-MB-231 and MDA-MB-468 cells, a general correlation between the uptake and silencing efficiency at the mRNA level was evident, but it appeared that the choice of the target rather than the cell type was more critical for consistent silencing. We conclude that siRNA therapy with well-characterized lipopolymers can be undertaken with multiple breast cancer cell phenotypes with similar efficiency, indicating the general applicability of non-viral RNAi in clinical management of molecularly heterogeneous breast cancers.
\end{abstract}

Key Words: Breast cancer, siRNA, delivery, lipopolymers, silencing. 


\section{INTRODUCTION}

After skin cancer, breast cancer is the most frequent cancer type diagnosed worldwide with North America having a relatively high incidence rate of $~ 125$ in 100,000 (2015) among women [1]. More than 41,000 breast cancer deaths were reported in the US alone in 2015 [2], although the mortality rates has been steadily declining since 1990s among the breast cancer patients of all ages [3]. Surgery and radiation therapy are among the front-line therapies for localized or early stage breast cancer, but chemotherapy is preferred in metastasized or advanced stage disease, including traditional broad-spectrum drugs that affect rapidly proliferating cells and molecular therapy that target specific proteins in signal transduction pathways [4-6]. However, even the most recent molecularly-targeted drugs may lose their efficacy as a result of resistance development [7]. The innate ability of transformed cells to adapt (plasticity) as well as the heterogeneous nature of the disease with extensive genetic diversity even within a single tumor [8] increase the chances of drug resistance. The triple negative breast cancers (TNBC), in particular, display increased recurrence rate and reduced long-term survival after conventional therapy. In Stage IV breast cancers, the 5-year survival rate precipitously drops to $\sim 22 \%$ and $\sim 20 \%$ among women and men, respectively [9]. Especially for the Stage IV disease, new treatment approaches are needed to manage these difficult-to-treat cases where the response to chemotherapeutic agents are limited.

The majority of the new generation of chemotherapeutic agents targets aberrant signaling pathways that support prolonged cell survival and enhanced proliferation. Receptor tyrosine kinases (RTKs) that activate Ras and Ras effectors [10], PI3K/Akt and MEK/ERK pathways, HER-2/neu signaling [11], certain cytokine receptors [12], and estrogen signaling network [13] are among breast cancer-specific mechanisms involved in aberrant signaling. As our 
understanding of breast cancer malignancy evolves and new targets are identified, developing a drug therapy based on conventional molecules will require a time-consuming de novo design approach to identify new active agents. Alternatively, one can rely on the innate RNA interference (RNAi) mechanism for therapeutic manipulation of mediators involved in enhanced cell proliferation and survival. One can readily down-regulate specific mRNAs involved in signaling, effectively reducing the intracellular levels of desired proteins at will. Unlike conventional drugs, RNAi and, its pharmacological mediator short interfering RNA (siRNA), allows one to target a multitude of molecules beyond the signaling pathways using a common platform: by changing the specificity (nucleotide sequence) of siRNA molecules, one can silence widely different mRNAs to restore the normal physiology using the same deliver platform. A wide range of targets were identified as a consequence of functional silencing in specific breast cancer cells; for example, Src kinase in MDA-MB-231 and Hs578T cells [14], anti-apoptotic Mcl-1 in MDA-MB-435 cells [15, 16], cell-cycle protein CDC20 in MDA-MB-231 cells [17], and cell shape regulators RhoGEF/RhoGAP in LM2 and MDA-MB-231 cells, and proteins involved in cell-matrix interactions in MCF-7 cells [18], to name a few. The efficacy of siRNA molecules in these studies relies on an effective delivery system that can transport siRNA into cells and release it intracellularly to exert its effect [19]. Past studies on siRNA therapy of breast cancers typically used one or two cell models and it is generally assumed that delivery systems used to formulate the siRNAs function similarly in different cell types. This assumption, however, is not tested in reported studies. It is imperative to understand common and differentiating features of siRNA delivery agents in a range of breast cancer cells to better predict the outcomes and to assess the full potential RNAi therapeutics. 
In this study, we undertook a systematic approach to study siRNA delivery in 6 different models of human breast cancer. The cell models selected for this study included: (i) MDA-MB231 cells, a triple negative breast cancer cell line with high levels of EGF receptor expression, (ii) MDA-MB-231-KRas-CRM cells, a version of the parent cell line certified for KRas mutation, (iii) MCF-7 cells, an epithelial-like cell with ER+ and PR+ phenotype, (iv) AU565 cells, an epithelial-like cell type with ER-, her2/neu+ overexpression, (v) MDA-MB-468 cells, epithelial-like triple negative cells with EGF receptor expression [20-22], and (vi) MDA-MB435 cells, an aggressive breast tumor line, with expression of both epithelial and melanocytic markers. By using a library of promising siRNA carriers, which are based on lipophilic polymers described previously [23], we investigated cellular delivery of siRNA among the chosen cell models. Since Janus Kinase 2 (JAK2) and Signal Transducer and Activator of Transcription 3 (STAT3) have been shown to play a major role in the proliferation and survival of breast cancer cells, and may even be involved in resistance against molecularly targeted drugs [24], we targeted JAK2 and STAT3 in this study and probed correlations between the delivery efficiency and silencing among different cell models. Our results allowed us to assess important features of the siRNA therapy intended for breast cancers using a range of siRNA carriers and cell models.

\section{EXPERIMENTAL METHODS}

\subsection{Materials}

The 2 kDa PEI (PEI2; Mn: 1.8 kDa, Mw: 2 kDa), 25 kDa PEI (PEI25; Mn: 10 kDa, Mw: $25 \mathrm{kDa}$ ), dimethyl sulfoxide (DMSO), stearoyl chloride (St), propionic acid (PrA), acryloyl chloride $\quad(\mathrm{AoCl}), \quad$ 1-ethyl-3-(3-dimethylaminopropyl) carbodiimide $\quad(\mathrm{EDC}), \quad \mathrm{N}-$ hydroxysuccinimide (NHS), chloroform $\left(\mathrm{CHCl}_{3}\right)$, methanol $(\mathrm{MeOH})$, Fluorescein 
isothiocyanate-dextran (Average molecular weight $=10,000 \mathrm{Da}$ ) and TRIzol reagent were obtained from Sigma-Aldrich (St. Louis, MO). Branched 1.2 kDa PEI (PEI1.2) and 0.6 kDa PEI (PEI0.6) were obtained from the Polysciences Inc. (Warrington, PA). Linoleyl chloride (LA) and $\alpha$-linoleoyl chloride ( $\alpha \mathrm{LA}$ ) were obtained from NU-CHEK PREP (Elysian, MN). DMEM (low glucose with L-glutamine), RPMI 1640 with L-glutamine, Hanks Balanced Salt Solution (HBSS), Fetal bovine serum (FBS), penicillin $(10000 \mathrm{U} / \mathrm{mL})$, streptomycin $(10 \mathrm{mg} / \mathrm{mL})$, and SYBR Green II were purchased from Life Technologies (Grand Island, NY). Scrambled negative control siRNA (Catalogue \# AM4635; Molecular weight: 13,300 Da), and 5'-carboxyfluorescein (FAM)-labeled negative control siRNA (Catalogue \# AM4620; Molecular weight: 13,676 Da) were provided by Ambion (Austin, TX). The siRNAs targeting Janus kinase 2 (JAK2; Catalogue \# SI02659657; Molecular Weight: 13255; Sense: 5'-CCAUCAUACGAGAUCUUAATT-3'; Antisense: 5'UUAAGAUCUCGUAUGAUGGCT-3') and signal transducer and activator of transcription 3 (STAT3; Catalogue \# SI02662368; Molecular Weight: 13325; Sense: 5'GCCUCUCUGCAGAAUUCAATT-3'; Antisense: 5'-UUGAAUUCUGCAGAGAGGCTG-3') was purchased from Qiagen (Valencia, CA). Primers for JAK2 (Forward: AAC TGC AGA TGC ACA TCA TTA CCT; Reverse: TCG AAA TTG GGC CAT GAC A) and STAT3 (Forward: ACA ACA TGT CAT TTG CTG AAA TCA; Reverse: TCC TTG GGA ATG TCA GGA TAG AG) were designed and ordered from Integrated DNA Technologies (IDT; Coralville, IA, USA). Master mixes iScript ${ }^{\mathrm{TM}}$ Reverse transcription Supermix, iTaq Universal SYBR Green Supermix, and all Western Blot requirements (including Trans-blot ${ }^{\circledR}$ Turbo $^{\mathrm{TM}}$ Cassettes, Trans-Blot ${ }^{\circledR}$ Turbo $^{\mathrm{TM}}$ Mini PVDF Transfer Packs, Clarity ${ }^{\mathrm{TM}}$ Western ECL Substrate, and 10\% MiniPROTEAN® TGX Stain-Free ${ }^{\mathrm{TM}}$ Protein Gels) were supplied by Bio-Rad (Hercules, CA). A monoclonal antibody against JAK2 (Rabbit Mab 3230; catalogue number: 3230) and anti-rabbit 
polyclonal secondary antibody HRP-linked (7074V) were supplied by Cell Signaling Inc. (Danvers, MA). A monoclonal antibody against STAT3 (Mouse Mab clone 232209; MAB1799) and anti-mouse polyclonal secondary antibody (Goat Anti-Mouse IgG HRP-linked; HAF007) were purchased from R\&D Systems (Minneapolis, MN). Pierce ${ }^{\mathrm{TM}}$ BCA protein assay kit was supplied by Thermo Scientific (Rockford, IL). All other materials were obtained from VWR (Radnor, PA).

\subsection{Cell Lines}

A panel of human breast cancer cell lines were selected for this study to represent a variety of characteristics and receptor expression profiles: (i) MDA-MB-231 (MDA231; triple negative, but expected to express EGFR; ATCC ${ }^{\circledR}$ HTB-26 ${ }^{\mathrm{TM}}$ ); (ii) MDA-MB-231, KRas-CRM (MDA231K; same as MDA-MB-231, certified for KRas mutation; ATCC ${ }^{\circledR}$ CRM-HTB-26 ${ }^{\mathrm{TM}}$ ); (iii) MDA-MB-468 (MDA468; triple negative, but over-expresses EGFR; ATCC ${ }^{\circledR}$ HTB-132'TM); (iv) AU565 (over-expresses HER2, and expected to express EGFR; ATCC ${ }^{\circledR}$ CRL-2351'TM); (v) MCF7 (estrogen and progesterone-positive, and expected to express HER2 and EGFR; ATCC ${ }^{\circledR}$ HTB-22 ${ }^{\mathrm{TM}}$ ), and; (vi) MDA-MB-435 (MDA-435): Long known as an estrogen-independent breast cancer cell line expressing HER-2 [25, 26]. MDA-435 cells have been source of controversy since it bears both epithelial and melanocytic markers [27, 28]. All cell lines except AU565 were cultured in DMEM low glucose medium, while AU565 was cultured in RPMI-1640 (both mediums supplemented with 10\% (v/v) FBS, $100 \mathrm{U} / \mathrm{mL}$ penicillin and $100 \mu \mathrm{g} / \mathrm{ml}$ streptomycin). All cell lines were maintained at $37^{\circ} \mathrm{C}$ and $5 \% \mathrm{CO}_{2}$ and were sub-cultured after reaching $80-90 \%$ confluency. Cells were discarded after 40 passages, and frozen cells (stored in liquid nitrogen) were thawed as replacement. 


\subsection{Polymer Synthesis and Characterization}

Hydrophobically-modified PEI derivatives were prepared by grafting hydrophobes onto PEIs via N-acetylation [29] or thioester linkages [30]. The lipids used for PEI substitution included caprylic acid (CA; C8), lauric acid (Lau; C12), palmitic acid (PA; C16) stearic acid (StA; C18), linoleic acid (LA; C18:2), alpha-linolenic acid ( $\alpha$ LA; C18:3) and cholesterol (Chol) (Figure 1A). The PEI used were either $0.6,1.2$ or $2.0 \mathrm{kDa}$ PEI obtained from commercial sources. As an example, to obtain $\mathrm{N}$-acylated conjugates, a lipid chloride (L-Cl, $2 \mathrm{mM}$ ) and PEI $(1 \mathrm{mM})$ were dissolved and incubated separately in ice-cold anhydrous chloroform for 30 minutes. Triethylamine $(100 \mu \mathrm{L})$ was added into the PEI solution and the solution was cooled for another 30 minutes in ice bath. The lipid chloride solution was added dropwise into the PEI solution while stirring on ice bath. Reaction mixture was then left stirring overnight ( 16 hours) at room temperature. The crude products were precipitated (x3) in ice-cold diethylether and dried under vacuum for 2 days. The structural composition of the polymers was analyzed by ${ }^{1} \mathrm{H}-\mathrm{NMR}$ spectroscopy (Bruker $300 \mathrm{MHz}$, Billerica, MA) using tetramethyl silane (TMS) as an internal standard in $\mathrm{D}_{2} \mathrm{O}$ to calculate the lipid substitution levels, which is summarized in Figure 1B. As expected, the degree of substitution increased with the feed ratio for all substitutes with an average yield between 0.50 and 0.55 , except LA that displayed a significantly lower average yield of 0.38. All the PEI derivatives used in this study were soluble in pure water.

\subsection{Binding Affinity to siRNA}

The affinity of modified polymers to bind to siRNA was determined by SYBR Green II dye exclusion assay, as reported previously [23]. Briefly, scrambled siRNA solutions (0.5 
$\mu \mathrm{g} / \mathrm{mL}$ ) were prepared in RNase-free water, and polymer/siRNA complexes were prepared at a variety of ratios (w/w: 0/1,0.1/1,0.25/1,0.5/1, 1/1,2/1, 2.5/1 and 5/1) via mixing siRNA and polymer solutions in saline solution. After 30 minutes of incubation at room temperature, $200 \mu \mathrm{L}$ of SYBR Green II solution (1:10,000 dilution in purified water) was added to the complexes. To determine the proportion of unbound siRNA, the fluorescence of the samples was quantified in a 96-well black plates $\left(\lambda_{\mathrm{ex}}: 485 \mathrm{~nm}, \lambda_{\mathrm{em}}: 527 \mathrm{~nm}\right)$. The percentage of siRNA bound to the peptide was plotted against the polymer/siRNA ratio, and the ratio required for $50 \%$ binding (BC50) was calculated based on the line equation of the linear portion of the curve.

\subsection{Cellular internalization}

The uptake of siRNA complexes into different human breast cancer cell lines was investigated via flowcytometry. Cells were seeded in 24-well plates 24-hours before the treatment $\left(0.5 \mathrm{~mL}\right.$ of $\sim 4 \times 10^{5}$ cells $\left./ \mathrm{mL}\right)$, and were incubated in $37^{\circ} \mathrm{C}$ and $5 \% \mathrm{CO}_{2}$. FAM-labeled siRNA was used to form complexes with the polymer library at 1:5 w/w ratio. After 30 minutes of incubation at room temperature, complexes were added to the wells for a final siRNA concentration of $36 \mathrm{nM}$. Cells were then incubated under culture conditions for 24 hours. After the incubation period, cells were washed with HBSS (x3) and trypsinized. The suspended cells were fixed with $3.7 \%$ formaldehyde solution, and the fluorescence was quantified by a flowcytometer (BD-FACSVerse, BD Biosciences; San Jose, CA). Calibration was performed by gating with the cell population treated with saline (i.e., "No Treatment"), so that the auto-

fluorescent cells represented $\sim 1 \%$ of the cell population. The percentage of cells with FAM fluorescence and the mean fluorescence in the selected cell population were determined. 


\subsection{Protein Silencing} uptake in the selected breast cancer cell lines. Dextran has been used as a marker for non-specific fluid-phase endocytosis [31] or macropinocytosis [32], where receptor interaction is not involved in triggering the internalization process. As an active transport indicator, dextran uptake is expected to diminish significantly at low temperatures $\left(\sim 4{ }^{\circ} \mathrm{C}\right)$. Cells were seeded $(0.5 \mathrm{~mL}$ or $\sim 5$ x $10^{5}$ cells $/ \mathrm{mL}$ ) and prepared for uptake studies as explained above. Immediately before the experiment, the culture media was removed from the wells, and fresh media (with or without fetal bovine serum) containing $0.5 \mathrm{mg} / \mathrm{mL}$ fluorescent-labeled dextran $(10 \mathrm{kDa})$ was added to the cells. The plates were incubated at 37 or $4{ }^{\circ} \mathrm{C}$ for 4 hours, and then the cells were prepared for flow cytometry as described above.

We also investigated the effect of two established uptake inhibitors on internalization of polymer/siRNA complexes and dextran. Chlorpromazine was used as a well-known inhibitor of clathrin-mediated endocytosis [33], and genistein was used for inhibition of caveolae-mediated uptake [34]. The cells were seeded and prepared for experiments as described above. Chlorpromazine and genistein were added to the cells at final concentrations of 20 and 50 $\mu \mathrm{g} / \mathrm{mL}$, respectively, and cells were incubated in $37^{\circ} \mathrm{C}$ for 30 minutes. The cells were then exposed to polymer/siRNA complexes or dextran for 4 hours in $37^{\circ} \mathrm{C}$ and were then trypsinized and prepared for flowcytometry as described before.

\footnotetext{
MDA231 and MDA468 cells were seeded in 6-well plates $\left(0.5 \mathrm{~mL}\right.$ of $\sim 3 \times 10^{5}$ cells $\left./ \mathrm{mL}\right)$, and incubated under regular cell growth conditions for 24 hours. Polymer/siRNA complexes were formed using scrambled siRNA (CsiRNA), or siRNA targeting Janus kinase 2 (JAK2) or
} 
signal transducer and activator of transcription 3 (STAT3) and selected polymers in the library at 1:5 w/w ratio. Polymer and siRNA were mixed in saline solution and then incubated for 30 minutes at room temperature. After gentle mixing, siRNA complexes were added to the serumcontaining medium for a final siRNA concentration of $50 \mathrm{nM}$, and the cells were incubated in 37 ${ }^{\circ} \mathrm{C}$ for 48 hours.

\subsection{Real-time PCR}

The efficacy of RNA interference was evaluated at the mRNA level using a previously reported quantitative PCR-based method [35]. Briefly, the cells treated with saline ("No Treatment" or NT), scrambled siRNA complexes (CsiRNA) or targeted siRNA complexes were lyzed using TRIzol reagent ( 1 mL for every $1 \times 10^{6}$ cells). The lysates were then incubated at room temperature for 5 minutes. Chloroform was added to the lysates ( $200 \mu \mathrm{L}$ for every $\mathrm{mL}$ of TRIzol), and mixed. The mixture was incubated for $2-3$ minutes at room temperature, and the aqueous phase was collected. In order to precipitate the total RNA, isopropanol was added to the mixture, and the precipitate was pelleted by centrifuge at $4{ }^{\circ} \mathrm{C}(12,000 \mathrm{~g}$ for $10 \mathrm{~min})$. The supernatant was removed, and pellet was washed with 75\% ethanol. Pelleted RNA was dissolved in RNase-free water, and the RNA concentration was determined by BioSpec-Nano spectrophotometer (Shimadzu, Columbia, MD). The extracted RNA was used to synthesize cDNA by reverse transcription. We used $0.5 \mu \mathrm{g}$ of RNA and iScript ${ }^{\mathrm{TM}}$ reverse transcription supermix. The cDNA synthesis was performed using C1000 Touch thermocycler (Bio-Rad, Hercules, CA), following the manufacturer's guidelines. For the RT-PCR analysis, CFX96TM optical module (Bio-Rad, Hercules, CA) was used, with human $\beta$-actin as the endogenous gene. Primers were validated before use for consistent efficiency independent of cDNA concentration 
and specificity by qPCR and gel electrophoresis, respectively. The number of cycles required to reach the threshold $\left(\mathrm{C}_{\mathrm{T}}\right)$, difference in $\mathrm{C}_{\mathrm{T}}$ for mRNA levels of targeted and endogenous protein $\left(\Delta \mathrm{C}_{\mathrm{T}}\right)$, and difference in $\Delta \mathrm{C}_{\mathrm{T}}$ for $\mathrm{NT}$ and treated groups $\left(\Delta \Delta \mathrm{C}_{\mathrm{T}}\right)$ were used to calculate relative quantities (RQs) for mRNA levels of targeted proteins. Silencing efficiency for qPCR experiments was calculated as:

$$
\text { Silencing Efficiency }(\%)=100-\left(\frac{R Q \text { for Study Group }}{R Q \text { for } N T \text { group }} \times 100\right)
$$

\subsection{Western Blot}

In order to confirm a corresponding decrease in protein expression for selected targets, JAK2 and STAT3 protein levels were quantified by Western blotting. Cell lysates were prepared according to a standard protocol using RIPA buffer. Briefly, treated cells were trypsinized, and re-suspended in medium. The cell suspension was then centrifuged at 800 RPM for $5 \mathrm{~min}$. The supernatant was discarded, ice-cold PBS was used to wash the cell pellet (x3), and $100 \mu \mathrm{L}$ of RIPA buffer was added to and gently mixed with $25 \mu \mathrm{L}$ of cell pellet. The lysates were incubated on ice for $60 \mathrm{~min}$, during which the tubes were sonicated for 3 minutes on ice and mixed every $10 \mathrm{~min}$. After the incubation period on ice, the tubes were centrifuged at $12,000 \mathrm{~g}$ for $15 \mathrm{~min}$ at 4 ${ }^{\circ} \mathrm{C}$. The supernatant was collected and transferred to pre-cooled tubes, and BSA assay was used to quantify total protein concentration according to manufacturer protocol. Briefly, $200 \mu \mathrm{L}$ of work reagent (50:1 Reagent A: Reagent B) was added to $25 \mu \mathrm{L}$ of BSA standard and unknown sample in triplicate and was transferred into microplate wells. Plate was placed on a plate shaker for 30 second and was then it was incubated at $37^{\circ} \mathrm{C}$, in $5 \% \mathrm{CO}_{2}$ for 30 minutes. The absorbance of the standards and samples was determined at $562 \mathrm{~nm}$ using microplate reader (SpectraMAX M5 microplate reader). For the blotting, $25 \mu \mathrm{g}$ total protein was loaded per well in a 10\% Mini- 
PROTEAN® TGX Stain-Free ${ }^{\mathrm{TM}}$ Protein gel using electrophoresis buffer (0.192 M glycine, 25 $\mathrm{mM}$ Tris, $0.1 \%$ SDS), and the gel electrophoresis was run for $30 \mathrm{~min}$ with 200 Volts. The gel was then transferred onto a Trans-Blot ${ }^{\circledR}$ Turbo ${ }^{\mathrm{TM}}$ Mini PVDF membrane (Catalog No. 1704156). Membranes were blocked in BSA 5\% for 3 hours, and were incubated overnight (at 4 ${ }^{\circ} \mathrm{C}$ ) with the primary anti-body (diluted 1:1000 in TBS-T). The membrane was then washed with TBS-T for five minutes (x6), and was then incubated with secondary HRP-linked antibody (diluted 1:1000 in TBS-T) for one hour followed by a similar washing step. Detection was done by ECL Detect Kit using ChemiDoc imager (Bio-Rad).

\subsection{Statistical Analysis}

The uptake studies and protein silencing were performed in triplicates, and the data were presented as mean \pm standard deviation. The significance of reported differences was evaluated using Student's t-test $(\mathrm{p}<0.05)$. Pearson's correlation coefficient was calculated for correlation studies, and its significance was determined by the t-test, according to the following equation:

$$
t=r \sqrt{\frac{n-2}{1-r^{2}}}
$$

where $\mathrm{r}$ and $\mathrm{n}$ are the correlation coefficient and the number of samples, respectively. The calculated value of $t$ was compared to the critical $t$ values for a given level of significance for each degree of freedom to determine the significance of the correlation. The mean fluorescence among different cell lines, different polymer molecular weights, and different fatty acid conjugates were compared by one-way ANOVA and Tukey post-hoc test $(\mathrm{p}<0.05)$. The box graphs were produced using Graphpad Prism 7.04. 


\section{RESULTS}

\subsection{Lipopolymers and siRNA Binding}

Figure 1 provides a summary of the lipopolymers used in this study. The polymers were derived from 0.6, 1.2 and $2.0 \mathrm{kDa}$ PEI with the lipids CA, Lau, PA, StA, LA, $\alpha$ LA and Chol substituted via an amide linkage or $\alpha$ LA substituted via a thioester linkage. The extents of lipid substitutions are summarized in Figure 1B and ranged from 0.7 to 2.8 lipids/PEI for PEI0.6, 0.4 to 3.6 lipids/PEI for PEI1.2 and 2.4 to 4.2 lipids/PEI for PEI2.0. All lipopolymers used in this study were water-soluble, since we used a water extraction step during purification to ensure solubility in aqueous medium. Based on ${ }^{1} \mathrm{H}-\mathrm{NMR}$ analysis, no apparent organic solvents were present in the final polymer preparations.

The binding of polymers to siRNA was determined by the well-established SYBR Green II binding assay. The polymer/siRNA ratio (w/w) that gave $50 \%$ binding $\left(\mathrm{BC}_{50}\right)$ was used as a quantitative value to compare the affinity of the conjugated polymers to bind to siRNA (Figure 2; $\mathrm{BC}_{50}$ values summarized in Table 1). Among the unconjugated polymers, PEI 2.0 had a slightly higher binding affinity $\left(\mathrm{BC}_{50}=0.09\right)$ as compared to PEI 0.6 and PEI $1.2\left(\mathrm{BC}_{50}\right.$ of 0.12 and 0.13 , respectively). Conjugation of the selected lipids increased the $\mathrm{BC}_{50}$ for all PEI polymers (apparent as a rightward shift in binding curves in Figure 2A); however, all lipopolymers showed complete binding and condensation at polymer/siRNA ratios of between 1 and 1.5. The properties of the substituted lipids did not seem to be a deciding factor for binding affinity, since the increase in $\mathrm{BC}_{50}$ did not correlate with the length of lipids. On the other hand, the level of substitution significantly affected the binding affinity, since the correlation between the substitution levels and the $\mathrm{BC}_{50}$ was significant for each type of PEI separately, and for the 
lipopolymer library as a whole (Figure 2B; $\mathrm{p}<0.05$ for individual molecular weights and $\mathrm{p}<$ 0.0005 for the polymer library).

\subsection{Cell Uptake of siRNA and Mechanistic Insight}

The level of siRNA internalization was evaluated for the polymer library in selected breast cancer cell lines by quantifying mean FAM-fluorescence per cell and percentage of cells positive for FAM-siRNA after exposure to FAM-siRNA/polymer complexes. The siRNA final concentrations, treatment periods and culture conditions were identical for all cell lines. Naïve un-modified polymers (PEI0.6, PEI1.2, and PEI2.0) were used as negative control, while PEI25 and a previously reported LA-modified PEI2.0 with significant in vitro and in vivo efficiency (designated as PEI-LA2.1; [36, 37]) were used as positive controls. Figure 3 summarizes the uptake results from the flow cytometry analysis. As expected, un-modified small MW PEIs did not give significant siRNA internalization (the highest mean fluorescence was 317 a.u. by PEI2.0 in AU565 cells, while the mean fluorescence was <220 a.u. for other naïve PEIs). Both PEI25 and PEI-LA2.1 showed efficient delivery in all cell lines (smallest mean fluorescence was 433 a.u. for PEI2.0-LA2.1 in MCF-7 cells). Among the modified PEIs, PEI0.6-CA4, PEI0.6-Lau4, PEI0.6-LA2, PEI1.2-Lau6, PEI1.2-LA4, PEI12.-LA8, PEI1.2-taLA6, PEI2.0-CA8, and PEI2.0Lau9 did not show give efficient siRNA delivery in the cells. PEI0.6-PA2 and PEI1.2-CA4 showed only moderate efficiency in one cell line (AU565 and MDA-468 cell line, respectively). However, PEI0.6-StA4, PEI0.6- $\alpha$ LA4, PEI1.2-Lau8, PEI1.2-PA8, PEI1.2-LA6, PEI1.2- $\alpha$ LA6, PEI2.0-PA9, and PEI2.0-StA6 were efficient in all cell lines, with the exception of MCF-7 cells. Other modified PEIs were not as consistent in their performance among different cell lines. For example, PEI1.2-Chol3 showed efficient in cellular uptake in MDA-231K (mean fluorescence of 
875 a.u.) and MDA-468 cells (mean fluorescence of 2695 a.u.; which was significantly higher than the positive controls); however, this polymer was not as effective in other three cells. The mean fluorescence achieved with PEI0.6-StA4 in MDA-231K and MDA-468 cells was by far the highest in the library (4480 and 7392 a.u., respectively). The percentage of positive cells showed similar trends for the polymer library (Figure 3B) and final results are summarized as a heat map in Figure 3C for a better visual comparison.

In order to further explore the determinants of cellular uptake, we categorically compared the mean uptake values among the different cell lines, the PEI MWs, and the lipids conjugated to PEIs (Figures 4A, B, and $\mathrm{C}$, respectively). The lowest mean fluorescence values were observed in MCF-7 cells, while the MDA-468 cells presented higher uptakes $(\mathrm{p}<0.003$ by one-way ANOVA between cell types). Among the base polymers, PEI0.6 showed the most variable uptake with different lipid substitutions with some of the highest observed uptakes. However, one-way ANOVA did not show a significant difference among the three MW modified PEIs, probably due to the high variability in cellular uptake with PEI0.6 polymers (Figure 4B). Finally, StA-substituted PEIs showed the highest uptake with significant ( $<<0.005$ by one-way ANOVA) differences from all other lipids.

The uptake of dextran was studied next at 4 and $37{ }^{\circ} \mathrm{C}$ in the presence and absence of serum to probe mechanism(s) of cellular internalization. Figure 5A summarizes the internalization of dextran among the selected cells at $37^{\circ} \mathrm{C}$. A different pattern of dextran uptake was seen than the uptake of polymer/siRNA complexes; (i) the variations in dextran uptake was relatively minor (within 2-fold) and (ii) dextran uptake in MCF-7 cells (that gave lowest polymer/siRNA uptake) was similar to MDA-231K and MDA-468 cells that gave the highest polymer/siRNA uptake. Mean dextran fluorescence was the highest in MDA-435 cells. 
Performing the dextran uptake study at $4^{\circ} \mathrm{C}$ reduced the mean fluorescence values associated with the cells by more than 10 -fold in all cell lines (data not shown), indicating active dextran uptake under cell culture $\left(37^{\circ} \mathrm{C}\right)$ conditions.

The correlations between the uptake levels of dextran and polymer/siRNA complexes in different cell lines are summarized in Figures 5B. No obvious correlation was evident in this analysis; i.e., the mean dextran uptake in individual cells did not generally correlate with uptake of polymer/siRNA complexes. Then, we explored a correlation between dextran uptake and uptake of siRNA complexes with individual polymers (Figure 5C). A variety of correlation coefficients were observed with the 5 cell lines included in the study but only correlation coefficients greater than $0.8\left(\mathrm{R}^{2}>0.64\right)$ are statistically significant, which was the case for PEI0.6-CA4 only $\left(\mathrm{R}^{2}=0.90\right)$. However, we highlighted all the polymers that demonstrated a moderate correlation (arbitrary $\mathrm{R}^{2}$ cut-off of 0.45 ) to dextran uptake with red boxes in Figure 5C. Unmodified PEI0.6 and PEI-1.2 and polymers PEI1.2-CA4, PEI1.2-LA8, PEI1.2tLA4, PEI1.2-taLA6, PEI2.0-CA8, PEI2.0-Lau9, and PEI-LA9 showed a moderate correlation with the dextran uptake. It is noteworthy that (i) these polymers were inefficient for siRNA delivery; ii) all CA-substituted PEIs were among this group; iii) the least correlation were observed for the PEI25 and PEI-LA2.1 $\left(\mathrm{R}^{2}=0.44\right.$ and 0.39 , respectively), which were the two reference reagents with high siRNA delivery efficiency; and iv) neither of StA- and Chol-substituted PEIs (effective delivery agents) showed even a moderate correlation with dextran uptake.

The uptake studies for selected polymers and dextran were repeated by using specific uptake inhibitors chlorpromazine and genistein. Polymers with high siRNA delivery efficiency (PEI0.6-StA4, PEI0.6- $\alpha$ LA4, PEI1.2-StA6, PEI1.2-Chol3, PEI1.2-LA6, and PEI2.0-StA6; Figure 6A) and polymers with moderate to high correlation with dextran uptake (PEI0.6-CA4, 
PEI1.2-CA4, PEI2.0-CA8, and PEI2.0-LA9; Figure 6B) were selected for this purpose. The dextran uptake was not affected by the selected inhibitors in the cell lines, except MCF7 cells. With experiments using more efficient lipopolymers, the extent of siRNA internalization was diminished by both chlorpromazine and genistein for all of the selected polymers in MDA-231 cells. The inhibitory effect was more significant for chlorpromazine in PEI0.6-StA4, PEI0.6$\alpha$ LA4, PEI1.2-StA6, and PEI1.2-Chol3 (the difference was not statistically significant in regards to percentage of siRNA-positive cells for PEI1.2-StA6, and PEI1.2-Chol3). A similar pattern was observed in other cells as well; an inhibitory effect was observed for different polymers, and this effect was more significant for chlorpromazine (not all differences were significant; see Figure 6A). The only exception was MDA- $231 \mathrm{~K}$ cells, where the inhibitory effect was not observed for most polymers and, with PEI2.0-StA6, genistein inhibition was higher than chlorpromazine. It is noteworthy that in these cells, the inhibitory action of the drugs was lower on the inefficient polymers (Figure 6A).

The inhibition results for polymers that demonstrated a moderate to high correlation with dextran uptake are summarized in Figure 6B. The inhibitory effect of chlorpromazine and genistein on siRNA cellular internalization was minimal in this case, as in dextran uptake. The only exception was with MCF7 cells, where PEI2.0-LA9 efficiency for delivering siRNA was diminished by chlorpromazine (but not genistein). This was the cell line where the dextran internalization was also affected by the inhibitors. Similar conclusions were reached when the uptake was based on percentage of siRNA-positive cells (Figure 1S and 2S; Supplementary data).

\subsection{Silencing Efficiency}


The important cancer therapeutic targets JAK2 and STAT3 were selected to probe silencing efficiency by selected polymers at mRNA and protein levels, and to explore correlations between cellular uptake and down-regulation of mRNA. Figure 7 summarizes the data on JAK2 silencing. The silencing was performed with the full library of polymers in both MDA-231 and MDA-468 cells and mRNA levels were normalized against non-treated (NT) cells (Figures 7Ai and 7Aiii, respectively). The extent of mRNA reduction was expected to correlate with the number of siRNA copies delivered to the cells, and in fact, a significant correlation was observed between the siRNA uptake (based on mean FAM-siRNA fluorescence) and silencing efficiency (\% of specific mRNA in treated cells compared to NT cells) in both MDA231 and MDA468 cells $(\mathrm{R} \sim 0.53$ and $\mathrm{R} \sim 0.66 ; \mathrm{p}<0.005$ and $\mathrm{p}<0.0005$, respectively; Figures 7Aii and 7Aiv). The results for a similar set of experiments performed with STAT3 are summarized in Figure 7B. Significant correlations were again observed for cell internalization and silencing efficiency $(\mathrm{R} \sim 0.82$ and $\mathrm{R} \sim 0.44$ in $\mathrm{MDA}-231$ and MDA-468; $\mathrm{p}<0.0005$ and $\mathrm{p}<0.01$, respectively; Figure 7Bii and 7Biv). Comparing the silencing efficiencies of JAK2 and STAT3 in the 2 cell types, a significant correlation was observed for the reduction in JAK2 mRNA levels between the 2 cell lines $(\mathrm{R} \sim 0.79, \mathrm{p}<0.005$; Figure $\mathbf{8 A i})$, as well as a significant correlation for the STAT3 siRNA treatment $(\mathrm{R} \sim 0.66 ; \mathrm{p}<0.0005$; Figure 8Aii). Finally, a correlation was investigated for down-regulation of the 2 targets in the same cells, and identical correlation coefficient was observed in MDA-231 cells $(\mathrm{R} \sim 0.41, \mathrm{p}<0.05$; Figure 8Bi) and MDA-468 cells $(\mathrm{R} \sim 0.41, \mathrm{p}<0.05 ;$ Figure 8Bii).

The silencing efficiencies based on protein levels (western blot) are summarized in Figure 9 for MDA-231 cells. A smaller set of polymers were selected for this study that were expected to give different levels silencing. Targeting with JAK2 siRNA and the chosen polymer, 
as expected, yielded different levels of protein reduction for the selected polymers, which correlated significantly with the efficiency observed at the mRNA level $(\mathrm{R} \sim 0.77$ for JAK2 and $\mathrm{R} \sim 0.82$ for STAT3, $\mathrm{p}<0.05$ and $\mathrm{p}<0.005$ respectively; Figure 9C). A significant correlation between the reduction in protein levels of JAK2 and STAT3 was also evident in the MDA231 cells $(\mathrm{R}=0.76 ; \mathrm{p}<0.05$; Figure 9D), similar to the correlation at the mRNA level (Figure 8Bii).

\section{DISCUSSION and CONCLUSIONS}

The main focus of this study was to explore the comparative performance of a library of lipopolymers intended for siRNA therapy in breast cancer cells. While we $[15,17,23,37,38]$ and others $[39,40]$ have pursued these polymers with specific cell models, targets important for breast cancer therapy and 'lead' polymers for delivery, comparative studies across cell lines and multiple targets are underreported. It is typical to focus on a single lipopolymer with a specific application [41,42] without exploring library-wide structure-function relationships. We were careful to include a library of polymers (with different backbones and lipid substituents) to ensure that our conclusions were not derived from particular polymers with unique performances. We observed that a similar degree of lipid substitution was obtained on PEIs with 0.6 to $2.0 \mathrm{kDa}$ backbone, with maximal 2-3 lipid substitutions for 0.6 kDa PEI and 3-4 lipid substitution for 1.2 and $2.0 \mathrm{kDa}$ PEI. Considering that (i) $\sim 14, \sim 28$ and $\sim 44$ amines (based on ethylenimine building block) are expected for 0.6, 1.2 and 2.0 kDa PEI, respectively, and that (ii) usually $\sim 25 \%$ of the amines are primary and readily available for substitution, it appears that the smallest PEI $(0.6 \mathrm{kDa})$ is fully substituted in our library, while the larger PEIs have spare primary amines that do not fully get substituted. Even with significantly increased amines in 2.0 
$\mathrm{kDa}$, there was no proportional increase in the extent of lipid substitution. It is likely that the lipids do not get substituted beyond a certain level due to steric hindrance or, more likely, the polymers with higher substitution levels were lost during processing of the final product in repeated ether-precipitation cycle (since hydrophobic substitution enhances ether solubility). Since we desired water-soluble conjugates, we did not attempt to collect any ether-soluble lipopolymers. A better control of substitution was previously achieved with the Michael's based addition reaction of hydrophobic acrylates to PEI [43], but this creates a different linker chemistry that may affect transfection activity. The lipid substitution uniformly reduced the extent of PEI binding to siRNA (irrespective of PEI backbone), requiring as much as $\sim 7$-fold increased lipopolymer amount to achieve full biding (based on $\mathrm{BC}_{50}$ values). The polymer backbone or the nature of lipid substituent, however, appeared to have a minimal effect on the $\mathrm{BC}_{50}$ values, which correlated with the extent of lipid substitution mainly. Others reported a lack of steric effect on siRNA binding with phospholipid-based substituents [44], distinctly different from our results.

Cellular delivery with lipopolymers was effective across different cell phenotypes and, unlike binding results, distinct differences among the polymers emerged when comparing performance in different cell types. MCF-7 cells emerged as the cell type that generally displayed least uptake with most lipopolymers not being that effective and only a few highly substituted PEIs (with no particular lipids) being slightly more effective. The reference polymers PEI25 and PEI2.0-LA2.1 were most effective in these cells (this specific PEI-LA was employed in previous studies with effective silencing efficiency $[15,36,37])$. MDA-231K cells on the other hand, displayed most uptake. We did not observe the MW of polymer backbone to affect the uptake to a significant degree but, among lipids, cholesterol, $\alpha$ LA and StA emerged as 
preferred substituents among the library lipopolymer members. Looking at overall correlations on uptake and substitution did not lead significant relationships in individual cell types $\left(\mathrm{R}^{2}<\right.$ 0.11 in all cases; not shown); this is indicative of specific lipids making a difference in siRNA delivery rather than the general hydrophobicity of polymeric carriers. This was the case for all cell types. At the onset of this study we wanted to reveal if there would be a universally effective polymer for siRNA delivery across different cell types; this appeared to be the case only for the two reference polymers (PEI25 and PEI2.0-LA2.1) in the study. The PEI25 is not a desirable carrier due to its high MW and associated toxicity on sensitive human cells, but its effectiveness has been more thoroughly validated in the literature by employing it not only for siRNA but also for pDNA delivery in a large number of cells. PEI2-LA2.1, on the other hand, emerged from our past studies whose effectiveness in MDA-435, MDA-231, MCR-7 and SUM149 cells were demonstrated. Having polymers more effective in certain cell types may be advantageous from a clinical perspective if a prior knowledge on the effective polymers for siRNA delivery could be gained; in that case, the siRNA delivery could be concentrated in transformed cells while minimizing delivery to non-target cells (e.g., normal tissue and clearance organs).

Dextran uptake was employed to inspect the fluid-phase uptake among the cells and its relevance to uptake of siRNA polyplexes. The fluid phase-mediated dextran and the siRNA uptake cannot be directly compared due to differences in fluorophore labeling and detection efficiencies of the labels (FAM vs. fluorescein). However, it could be seen that, unlike the siRNA uptake values with the lipopolymer library, the dextran uptake represented a narrower range ( 2-fold among the cell types), indicating relatively little differences among the cell types when it comes to non-specific fluid-phase uptake. No general correlation was evident between the dextran and siRNA uptake indicating different mechanisms to be at play for the uptake of 
these two macromolecules (with one exception noted at the end of this paragraph). This was further confirmed with the use of chemical inhibitors of endocytosis that gave distinctly different effects on siRNA uptake (inhibitory effect) and dextran uptake (no effect). We previously employed normal human foreskin fibroblast cells, selectively inhibited clathrin-dependent endocytosis (CME), caveolin-mediated endocytosis (CvME), and macropinocytosis, and showed that a model lipopolymer (PEI-LA2.1 used in this study) utilized primarily CME pathway and to a less degree CvME pathway [38], while PEI25 was able to utilize all three pathways (again attesting to its potential to act on broad population of cells). Therefore, the lipopolymers are also expected to act through both $\mathrm{CME}$ and $\mathrm{CvME}$ pathways and the fact that the two inhibitors specifically chosen to target these pathways (chlorpromazine for CME and genistein for CvME) equally inhibited the uptake in all cells (note that MDA-231, MDA-468, AU565, MCF-7, MDA435 cells were all inhibited and MDA-231K cells gave inhibition for more effective lipopolymers) suggests that both pathways are utilized to a similar degree by more effective lipopolymers. For the relatively less-effective polymers, we were able to observe a correlation between the (low) siRNA uptake and dextran uptake (see Figure 5C), suggesting that these polymers do not enter the cells vie either $\mathrm{CME}$ or $\mathrm{CvME}$ and that fluid phase macropinocytosis is employed in their case, which leads to low delivery efficiency. Detailed mechanistic studies on uptake of nucleic acid complexes are missing for other lipopolymers reported in the literature.

A range of polymers were also effective in silencing the targets JAK2 and STAT3 in two of the chosen cell types, MDA-231 and MDA-438. The silencing efficiency in general showed a good correlation with the uptake efficiency in both cell types with a similar pattern. Two types of lipopolymers emerged from these studies, (i) ones where a good correlation was evident for polymers that gave high uptake and (ii) a sub-group of polymers that gave relatively low delivery 
but still displayed silencing efficiency that was comparable to the lipopolymers with high siRNA delivery. It appeared that while the delivery was paramount for improved silencing, there may be selective polymers that are particularly efficient in overcoming intracellular hurdles to silencing with minimal delivery. The exact steps these lipopolymers take have not been elucidated in this study, but it is likely that they display increased endosomal escape or fast dissociation kinetics inside the cytoplasm to engage and assemble the RISC complex. One particular polymers PEI0.6-LA2 was an example for low delivery and high silencing carrier and further studies to identify the mechanisms behind such performance will be beneficial. Two important issues related to therapeutic targeting that we explored are (i) whether a specific polymer could be used to target multiple targets in the same cell, and (ii) whether the same target could be silenced to the same efficiency in different cell types. The latter will depend on the efficiency of delivery in different cell types and we expected the silencing differences between cell types to be greater since delivery efficiency would be different. Our observations were to the contrary; the correlations for specific target silencing was better between the two cell types investigated while the correlation for silencing JAK2 and STAT3 within the same cell type was inferior (Figure 8). This was indicative of target being more critical in achieving silencing than the cell type and possibly indicates the kinetics of RNAi machinery to be significant. Stability of different siRNAs in cytoplasm, synthesis and turn-over rate of target mRNA, cooperativity (no of siRNA target sites) and cleavage kinetics are all factors that can contribute to intra-cellular variation for specific target silencing [45, 46]. Differential regulation of target genes, especially upregulation as we observed in breast cancer cells [47], is another factor contributing to silencing efficiency of different targets. While mRNA levels did not always correlate to silencing efficiency at the 
protein level, we confirmed that the protein levels (using JAK2 as target protein) were similarly reduced in our study groups.

In conclusion, lipopolymers were found to be versatile carriers of siRNA capable of delivering effective dose of siRNA to a range of breast cancer cells. Despite some differences in the delivery efficiency among the cell types investigated, the mechanistic details of the delivery appeared to be similar, with CME and CvME significantly involved in the internalization of the polyplexes, while fluid-phase endocytosis not being greatly significant for effective polymers. Specific target silencing was generally correlated to the delivery across the library of lipopolymers, but we did notice the presence of lipopolymers that achieved high silencing with minimal siRNA delivery. Finally, we noted that silencing specific targets in different cell types were more uniformly achieved as compared to targeting different targets in the same cell type. This highlights the importance of the mediator to be targeted by the siRNA in implementing the clinical therapy.

\section{ACKNOWLEDGEMENTS}

This study was supported by an Operating Grant from the Canadian Institutes of Health Research (CIHR; HU), a Discovery Grant from the Natural Sciences and Engineering Research Council of Canada (NSERC; HU), and an Operating Grant from the Canadian Breast Cancer Foundation (CBCF; HU). We acknowledge the technical help provided by Dr. V. Somayaji in generating the ${ }^{1} \mathrm{H}-\mathrm{NMR}$ spectrums.

\section{CONFLICT OF INTEREST}


Remant KC and Hasan Uludag are founders of a company (RJH Biosciences Inc., Edmonton, Alberta) intended to commercialize the described polymers for transfection. 


\section{LEGENDS}

Figure 1. (A) Synthesis schemes for lipopolymers prepared for this study. Representative products are shown for $\mathrm{N}$-acylation (i) and thioester (ii) reactions with the linoleic acid, while the list of lipids employed is shown in (iii). (B) Lipopolymer compositions (no of lipid substitution per PEI) and corresponding $\mathrm{BC}_{50}$ values. The polymer designations show the $\mathrm{MW}$ of the PEI backbone $(0.6,1.2$ or $2.0 \mathrm{kDa}$ ), linkage chemistry ( $\mathrm{N}$-acylation in most cases and thioester indicated with ' $t$ '), lipid substituent (CA, Lau, PA, StA, LA, aLA and Chol) and the feed ratio used in synthesis (2, 3, 4, 6, 8 and 9). For example, PEI0.6-CA4 indicates 0.6 kDa PEI modified with CA at a feed ratio of 4 (lipid to PEI).

Figure 2. Binding affinities of polymers with siRNA as determined by a Sybr Green II binding assay. The siRNA/polymer complexes were formed and the bound percentage of siRNA was determined based on fluoresecence measurements. (A) Actual siRNA binding curves as a function of polymer:siRNA ratio incubated (w/w), which are grouped for lipopolymers with different PEI backbones. (B) Correlations between the lipid substitution and the extent of siRNA affinity, as determined by $\mathrm{BC}_{50}$. Correlations for 3 separate lipopolymers (with $0.6,1.2$ and 2.0 $\mathrm{kDa}$ backbones) were shown as well as combined values.

Figure 3. The siRNA delivery to 5 separate breast cancer cell types with the lipopolymer library. The siRNA uptake was characterized based on the mean FAM-siRNA fluorescence per cell (A), and the percentage of FAM-siRNA-positive cell population (B). The uptake was determined 24 hours after incubation of FAM-siRNA complexes and quantitated by flow cytometry. (C) Heat map showing the effectiveness of polymers for siRNA delivery across the 5 cell types used. Note that uptake was arbitrarily categorized into 4 groups, based on mean FAM-siRNA levels or percentage of FAM-siRNA positive cell population.

Figure 4. Sub-group analysis of siRNA delivery as a function of cell line employed (A), the MW of the PEI backbone used for lipid substitution (B) and the actual lipid substituted (C). Overall, MCF-7 cells showed the lowest siRNA uptake compared to other selected breast cancer cell lines, and the level of internalization with the polymer library was higher in MDA-468 and MDA-231K cells. Except two outsiders, the effect of hydrophobic modification was similar on PEIs with different molecular weights. Among the selected hydrophobic moieties, stearic acid, cholesterol, and $\alpha$-linoleic acids showed the highest impact on the performance of the polymers in cellular internalization of siRNA.

Figure 5. Dextran uptake in the breast cancer cell lines based on uptake of Fluorescein-dextran using flow cytometry. (A) Mean dextran uptake in the breast cancer cells incubated in serum-free and serum-containing medium. (B) Correlation of dextran uptake with siRNA uptake for the breast cancer cells. siRNA uptake was based on either mean siRNA levels in cells (i) or percentage of siRNA positive cell population (ii). (C) Correlation between dextran uptake and siRNA uptake for individual polymers. Each graph utilized uptake data from 5 different cell types tested with each polymer. The boxed graphs show the relatively stronger correlations for specific polymers between the dextran and siRNA uptake. 
Figure 6. Effect of endocytosis inhibitors on the uptake of siRNA complexes. The mean siRNA uptake per cell are summarized for different types of cells exposed to different lipopolymer complexes of siRNA. (A) Results with most effective siRNA delivery agents are summarized in MDA-231 cells, MDA-231K cells, MDA-438 cells, AU565 cells, MCF-7 cells, and MDA-435 cells. The uptake is shown without an inhibitor treatment and with the treatment of cells with chlorpromazine and genistein as the inhibitors. (B) Results with relatively ineffective siRNA delivery agents that correlated with dextran uptake are summarized in the same cells. * indicates significant difference with "without inhibitor" group, while $\dagger$ indicates a significantly higher inhibition of uptake than the other inhibitor $(\mathrm{p}<0.05)$.

Figure 7. (A) The effect of delivering JAK2 specific siRNA in MDA-231 cells (i and ii) and MDA-468 cells (iii and iv). The cells were treated with either control (non-specific) siRNA or a JAK2 specific siRNA formulated with the lipopolymers and then the cells were harvested after 48 hours to measure the levels of JAK2 mRNA by qPCR. The siRNAs were prepared with the indicated lipopolymers at ratio of 5:1 (polymer:siRNA) and siRNA concentration of $50 \mathrm{nM}$. The extent of silencing was compared to non-treated cells where the JAK2 mRNA levels were taken as $100 \%$. The correlation between the extent of siRNA silencing and siRNA uptake are summarized for MDA-231 cells (ii) and MDA-468 cells (iv). (B) The effect of delivering STAT3 specific siRNA in MDA-231 cells (i and ii) and MDA-468 cells (iii and iv). The experimental conditions and data analysis were the same as the conditions in (A).

Figure 8. (A) Correlation in JAK2 (i) and STAT3 (ii) silencing efficiency between the MDA231 cells and MDA-468 cells (original data presented in Figure 7). Expression levels of targeted proteins (expressed as RQ compared to cells treated with scrambled siRNA) were used for the correlations. Significant correlations were evident in i and ii. (B) Correlations between the JAK2 and STAT3 silencing in (i) MDA-231 cells and (ii) MDA-468 cells (original data presented in Figure 7). Note the better correlations in A, indicating that silencing was better correlated with the choice of the target rather than the within individual cell types.

Figure 9. The protein levels (by western plot) for cells treated with JAK2 (A) and STAT3 (B) specific siRNAs. The JAK2 and STAT3 protein levels were normalized with the $\beta$-actin levels (as housekeeping protein) and used as the extent of silening at the protein level. The analysis were performed in MDA-231 cells after 24 hours of siRNA treatment (50 nM and 5:1 ratio) and correlated to the qPCR-based silencing analysis at the mRNA level (right graphs). (C) Correlaton between the mRNA and protein levels for JAK2 $(\mathrm{R}=0.77)$ and STAT3 $(\mathrm{R}=0.82)$ after specific siRNA treatment. (D) Correlation between the JAK2 protein and STAT3 protein levels after specific siRNA delivery with the same polymeric carrier. 


\section{REFERENCES}

[1] Group USCSW. U.S. Cancer Statistics Data Visualizations Tool, based on November 2017 submission data (1999-2015). In: U.S. Department of Health and Human Services CfDCaPaNCl, editor.June 2018.

[2] Siegel RL, Miller KD, Jemal A. Cancer statistics, 2015. CA Cancer J Clin 2015;65:5-29.

[3] DeSantis CE, Ma J, Goding Sauer A, Newman LA, Jemal A. Breast cancer statistics, 2017, racial disparity in mortality by state. CA Cancer J Clin 2017;67:439-48.

[4] Denkert C, Liedtke C, Tutt A, von Minckwitz G. Molecular alterations in triple-negative breast cancerthe road to new treatment strategies. Lancet 2017;389:2430-42.

[5] Loibl S, Gianni L. HER2-positive breast cancer. Lancet 2017;389:2415-29.

[6] Turner NC, Neven P, Loibl S, Andre F. Advances in the treatment of advanced oestrogen-receptorpositive breast cancer. Lancet 2017;389:2403-14.

[7] Mohamed A, Krajewski K, Cakar B, Ma CX. Targeted therapy for breast cancer. Am J Pathol 2013;183:1096-112.

[8] Joseph C, Papadaki A, Althobiti M, Alsaleem M, Aleskandarany MA, Rakha EA. Breast cancer intratumour heterogeneity: current status and clinical implications. Histopathology 2018;73:717-31.

[9] Survival statistics for breast cancer. Canadian Cancer Society; 2018.

[10] Roderick HL, Cook SJ. Ca2+ signalling checkpoints in cancer: remodelling $\mathrm{Ca} 2+$ for cancer cell proliferation and survival. Nat Rev Cancer 2008;8:361-75.

[11] Jiang W, Jin Z, Zhou F, Cui J, Wang L, Wang L. High co-expression of Sp1 and HER-2 is correlated with poor prognosis of gastric cancer patients. Surg Oncol 2015;24:220-5.

[12] Vainchenker W, Constantinescu SN. JAK/STAT signaling in hematological malignancies. Oncogene 2013;32:2601-13.

[13] Tyson JJ, Baumann WT, Chen C, Verdugo A, Tavassoly I, Wang Y, et al. Dynamic modelling of oestrogen signalling and cell fate in breast cancer cells. Nat Rev Cancer 2011;11:523-32.

[14] Tzeng YT, Liu PF, Li JY, Liu LF, Kuo SY, Hsieh CW, et al. Kinome-Wide siRNA Screening Identifies SrcEnhanced Resistance of Chemotherapeutic Drugs in Triple-Negative Breast Cancer Cells. Front Pharmacol 2018;9:1285.

[15] Aliabadi HM, Mahdipoor P, Uludag H. Polymeric delivery of siRNA for dual silencing of Mcl-1 and Pglycoprotein and apoptosis induction in drug-resistant breast cancer cells. Cancer Gene Ther 2013;20:169-77.

[16] Garg SM, Falamarzian A, Vakili MR, Aliabadi HM, Uludag H, Lavasanifar A. Polymeric micelles for MCL-1 gene silencing in breast tumors following systemic administration. Nanomedicine (Lond) 2016;11:2319-39.

[17] Parmar MB, Aliabadi HM, Mahdipoor P, Kucharski C, Maranchuk R, Hugh JC, et al. Targeting Cell Cycle Proteins in Breast Cancer Cells with siRNA by Using Lipid-Substituted Polyethylenimines. Front Bioeng Biotechnol 2015;3:14.

[18] Fokkelman M, Balcioglu HE, Klip JE, Yan K, Verbeek FJ, Danen EH, et al. Cellular adhesome screen identifies critical modulators of focal adhesion dynamics, cellular traction forces and cell migration behaviour. Sci Rep 2016;6:31707.

[19] Aliabadi HM, Landry B, Sun C, Tang T, Uludag H. Supramolecular assemblies in functional siRNA delivery: where do we stand? Biomaterials 2012;33:2546-69.

[20] Hevir N, Trost N, Debeljak N, Rizner TL. Expression of estrogen and progesterone receptors and estrogen metabolizing enzymes in different breast cancer cell lines. Chem Biol Interact 2011;191:206-16. [21] Smith SE, Mellor P, Ward AK, Kendall S, McDonald M, Vizeacoumar FS, et al. Molecular characterization of breast cancer cell lines through multiple omic approaches. Breast Cancer Res 2017;19:65. 
[22] Jiang G, Zhang S, Yazdanparast A, Li M, Pawar AV, Liu Y, et al. Comprehensive comparison of molecular portraits between cell lines and tumors in breast cancer. BMC Genomics 2016;17 Suppl 7:525. [23] Aliabadi HM, Landry B, Bahadur RK, Neamnark A, Suwantong O, Uludag H. Impact of lipid substitution on assembly and delivery of siRNA by cationic polymers. Macromol Biosci 2011;11:662-72. [24] Bousoik E, Montazeri Aliabadi H. "Do We Know Jack" About JAK? A Closer Look at JAK/STAT Signaling Pathway. Front Oncol 2018;8:287.

[25] Bajo AM, Schally AV, Krupa M, Hebert F, Groot K, Szepeshazi K. Bombesin antagonists inhibit growth of MDA-MB-435 estrogen-independent breast cancers and decrease the expression of the ErbB-2/HER-2 oncoprotein and c-jun and c-fos oncogenes. Proc Natl Acad Sci U S A 2002;99:3836-41.

[26] Datta D, Flaxenburg JA, Laxmanan S, Geehan C, Grimm M, Waaga-Gasser AM, et al. Ras-induced modulation of CXCL10 and its receptor splice variant CXCR3-B in MDA-MB-435 and MCF-7 cells: relevance for the development of human breast cancer. Cancer Res 2006;66:9509-18.

[27] Korch C, Hall EM, Dirks WG, Ewing M, Faries M, Varella-Garcia M, et al. Authentication of M14 melanoma cell line proves misidentification of MDA-MB-435 breast cancer cell line. Int J Cancer 2018;142:561-72.

[28] Prasad VV, Gopalan RO. Continued use of MDA-MB-435, a melanoma cell line, as a model for human breast cancer, even in year, 2014. NPJ Breast Cancer 2015;1:15002.

[29] Neamnark A, Suwantong O, Bahadur RK, Hsu CY, Supaphol P, Uludag H. Aliphatic lipid substitution on $2 \mathrm{kDa}$ polyethylenimine improves plasmid delivery and transgene expression. Mol Pharm 2009;6:1798-815.

[30] Bahadur KCR, Kucharski C, Uludag H. Additive nanocomplexes of cationic lipopolymers for improved non-viral gene delivery to mesenchymal stem cells. J Mater Chem B 2015;3:3972-82.

[31] Thompson DB, Villasenor R, Dorr BM, Zerial M, Liu DR. Cellular uptake mechanisms and endosomal trafficking of supercharged proteins. Chem Biol 2012;19:831-43.

[32] Li L, Wan T, Wan M, Liu B, Cheng R, Zhang R. The effect of the size of fluorescent dextran on its endocytic pathway. Cell Biol Int 2015;39:531-9.

[33] Lu JJ, Langer R, Chen J. A novel mechanism is involved in cationic lipid-mediated functional siRNA delivery. Mol Pharm 2009;6:763-71.

[34] Rejman J, Bragonzi A, Conese M. Role of clathrin- and caveolae-mediated endocytosis in gene transfer mediated by lipo- and polyplexes. Mol Ther 2005;12:468-74.

[35] Do H, Sharma M, El-Sayed NS, Mahdipoor P, Bousoik E, Parang K, et al. Difatty Acyl-Conjugated Linear and Cyclic Peptides for siRNA Delivery. ACS Omega 2017;2:6939-57.

[36] Aliabadi HM, Mahdipoor P, Kucharsky C, Chan N, Uludag H. Effect of siRNA pre-Exposure on Subsequent Response to siRNA Therapy. Pharm Res 2015;32:3813-26.

[37] Aliabadi HM, Maranchuk R, Kucharski C, Mahdipoor P, Hugh J, Uludag H. Effective response of doxorubicin-sensitive and -resistant breast cancer cells to combinational siRNA therapy. J Control Release 2013;172:219-28.

[38] Hsu CY, Uludag H. Cellular uptake pathways of lipid-modified cationic polymers in gene delivery to primary cells. Biomaterials 2012;33:7834-48.

[39] Guo G, Tortorella M, Zhang B, Wang Y. Disassembly of micelle-like polyethylenimine nanocomplexes for siRNA delivery: High transfection efficiency and reduced toxicity achieved by simple reducible lipid modification. J Colloid Interface Sci 2017;504:633-44.

[40] Tripathi SK, Gupta N, Mahato M, Gupta KC, Kumar P. Selective blocking of primary amines in branched polyethylenimine with biocompatible ligand alleviates cytotoxicity and augments gene delivery efficacy in mammalian cells. Colloids Surf B Biointerfaces 2014;115:79-85.

[41] An S, He D, Wagner E, Jiang C. Peptide-like Polymers Exerting Effective Glioma-Targeted siRNA Delivery and Release for Therapeutic Application. Small 2015;11:5142-50. 
[42] Liu J, Van S, Ma N, Yu L. Efficient systemic delivery of siRNA to the mouse liver by pegylated lipopolymer. Int J Pharm 2012;427:58-63.

[43] Philipp A, Zhao X, Tarcha P, Wagner E, Zintchenko A. Hydrophobically modified oligoethylenimines as highly efficient transfection agents for siRNA delivery. Bioconjug Chem 2009;20:2055-61.

[44] Navarro G, Essex S, Sawant RR, Biswas S, Nagesha D, Sridhar S, et al. Phospholipid-modified polyethylenimine-based nanopreparations for siRNA-mediated gene silencing: implications for transfection and the role of lipid components. Nanomedicine 2014;10:411-9.

[45] Cuccato G, Polynikis A, Siciliano V, Graziano M, di Bernardo M, di Bernardo D. Modeling RNA interference in mammalian cells. BMC Syst Biol 2011;5:19.

[46] Dornseifer S, Willkomm S, Far RK, Liebschwager J, Beltsiou F, Frank K, et al. RNAi revised--target mRNA-dependent enhancement of gene silencing. Nucleic Acids Res 2015;43:10623-32.

[47] Aliabadi HM, Mahdipoor P, Bisoffi M, Hugh JC, Uludag H. Single and Combinational siRNA Therapy of Cancer Cells: Probing Changes in Targeted and Nontargeted Mediators after siRNA Treatment. Mol Pharm 2016;13:4116-28. 
A

(i) $\mathrm{N}$-acylated conjugate

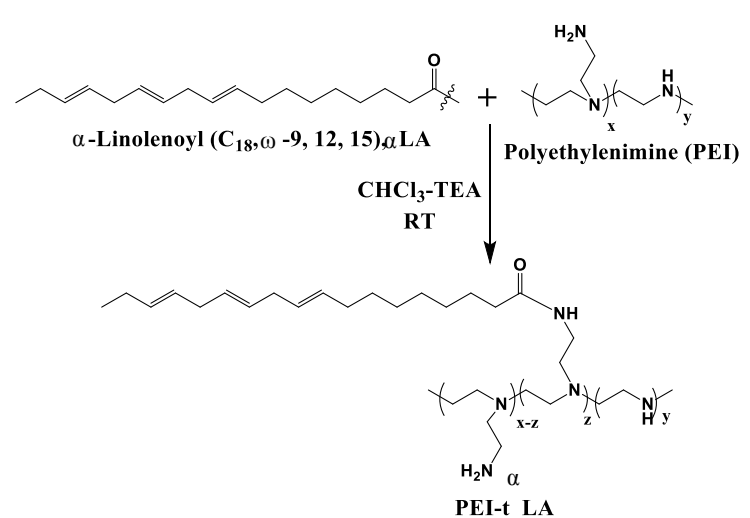

(iii) List of lipids

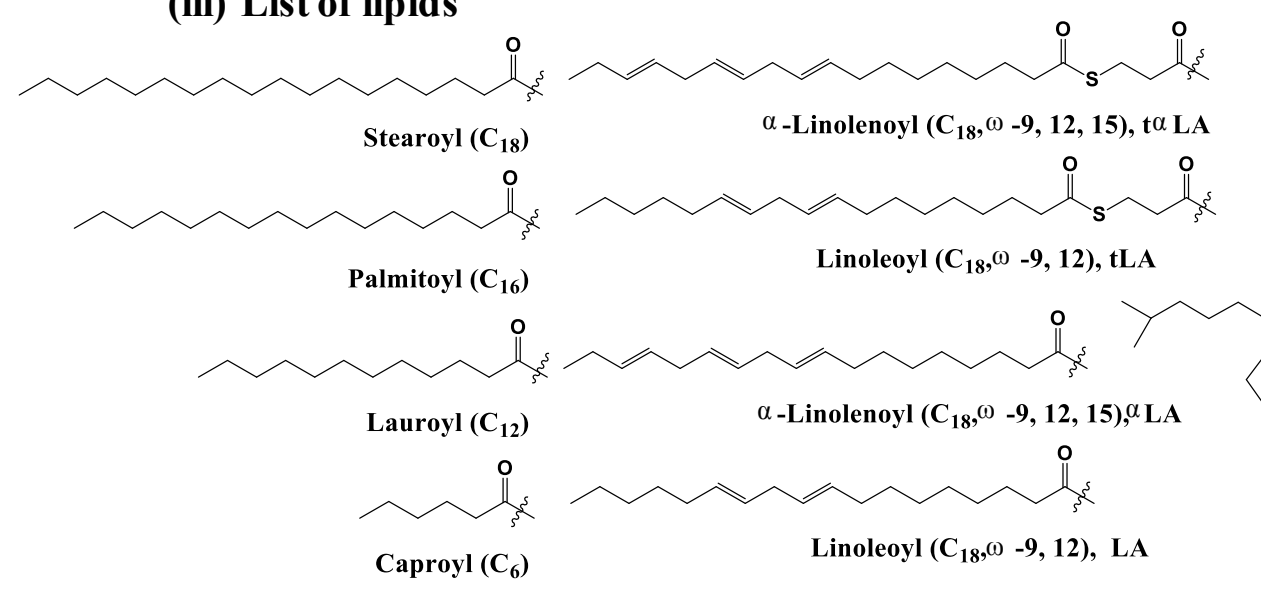

(ii) Thioester conjugate

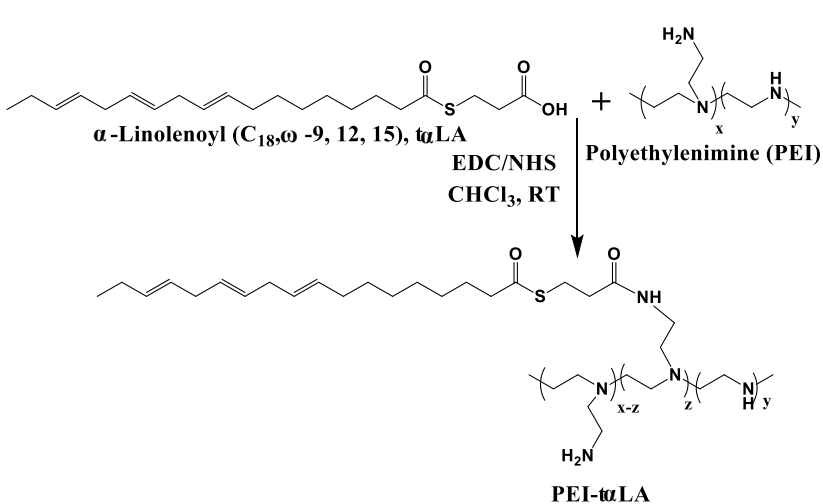

PEI-taLA

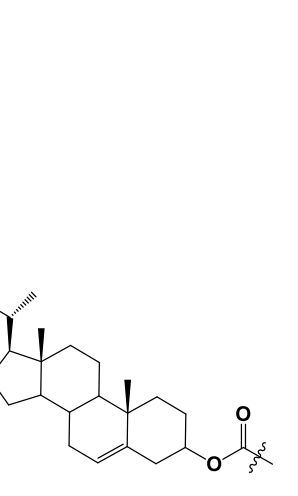

Cholesteryl $\left(\mathrm{C}_{28}\right)$
Polymer ID Substitution $\mathrm{BC}_{50}$

\begin{tabular}{l|c|c|c|} 
B & PEI 0.6 & 0 & 0,12
\end{tabular}

\begin{tabular}{|l|r|r}
\hline PEI 0.6-CA4 & 2,46 & 1,4 \\
\hline
\end{tabular}

\begin{tabular}{ll|l} 
PEI 0.6-Lau4 & 2,75 & 0,22
\end{tabular}

\begin{tabular}{|l|l|l|}
\hline PEI 0.6-PA2 & 0,72 & 0,17 \\
\hline
\end{tabular}

\begin{tabular}{l|l|l|}
\hline PEI 0.6-St4 & 2,55 & 0,84 \\
\hline
\end{tabular}

\begin{tabular}{|l|l|l|}
\hline PEI 0.6-LA2 & 0,71 & 0,19 \\
\hline
\end{tabular}

\begin{tabular}{|l|l|l|} 
PEI 0.6- aLA4 & 2,3 & 0,94 \\
\hline
\end{tabular}

\begin{tabular}{|l|l|l|}
\hline PEI 0.6- Chol2 & 1,08 & 0,42 \\
\hline
\end{tabular}

\begin{tabular}{|l|l|l} 
PEI 1.2 & 0 & 0,13 \\
\hline
\end{tabular}

\begin{tabular}{l|l|l} 
PEI 1.2-CA4 & 1,87 & 0,26 \\
\hline
\end{tabular}

\begin{tabular}{|l|r|r|}
\hline PEI 1.2-lau6 & 2,54 & 1,46 \\
\hline
\end{tabular}

\begin{tabular}{l|l|l} 
PEI 1.2-lau8 & 3,6 & 1,33 \\
\hline
\end{tabular}

\begin{tabular}{l|l|l|} 
PEI 1.2-PA8 & 3,44 & 1,19 \\
\hline
\end{tabular}

$\begin{array}{lll}\text { PEI 1.2- St6 } & 3,32 & 1,26\end{array}$

\begin{tabular}{l|l|l|}
\hline PEI 1.2- LA2 & 0,4 & 0,19 \\
\hline
\end{tabular}

\begin{tabular}{|l|l|l|}
\hline PEI 1.2- LA4 & 1,62 & 0,46 \\
\hline
\end{tabular}

\begin{tabular}{l|l|l|}
\hline PEI 1.2-LA6 & 2,55 & 0,93 \\
\hline
\end{tabular}

\begin{tabular}{|l|l|l|}
\hline PEI 1.2-LA8 & 3,53 & 0,46 \\
\hline
\end{tabular}

\begin{tabular}{ll|l} 
PEI 1.2-aLA6 & 3,16 & 0,31
\end{tabular}

\begin{tabular}{l|l|l|}
\hline PEI 1.2-tLA4 & 2,77 & 0,64 \\
\hline
\end{tabular}

$\begin{array}{lll}\text { PEI 1.2-taLA6 } & 3,2 & 0,58\end{array}$

\begin{tabular}{|l|l|l|}
\hline PEI 1.2-Chol3 & 2,21 & 0,63 \\
\hline
\end{tabular}

\begin{tabular}{l|l|l} 
PEI 2 & 0 & 0,09 \\
\hline
\end{tabular}

\begin{tabular}{l|l|l|} 
PEI 2-CA8 & 2,83 & 0,28 \\
\hline
\end{tabular}

\begin{tabular}{|l|l|l|}
\hline PEI 2-Lau9 & 4,24 & 1,09 \\
\hline
\end{tabular}

\begin{tabular}{l|l|l|} 
PEI 2-PA9 & 3,4 & 1,23 \\
\hline
\end{tabular}

\begin{tabular}{|l|l|l|}
\hline PEI2-Sta6 & 3,14 & 0,54 \\
\hline
\end{tabular}

\begin{tabular}{l|l|l|} 
PEI2-LA9 & 3,2 & 0,82 \\
\hline
\end{tabular}

\begin{tabular}{|l|l|l|}
\hline PEI2-aLA4 & 2,72 & 0,34 \\
\hline
\end{tabular}

\begin{tabular}{l|l|l|}
\hline PEI2-Chol4 & 2,36 & 0,34 \\
\hline
\end{tabular} 


\section{Figure 2A}
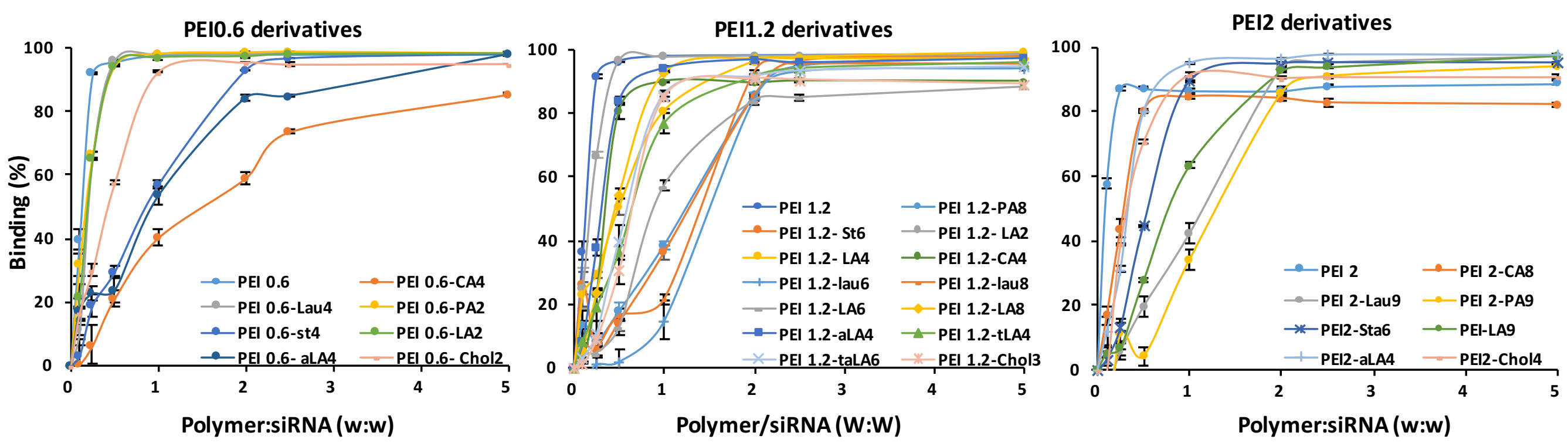
Figure 2B

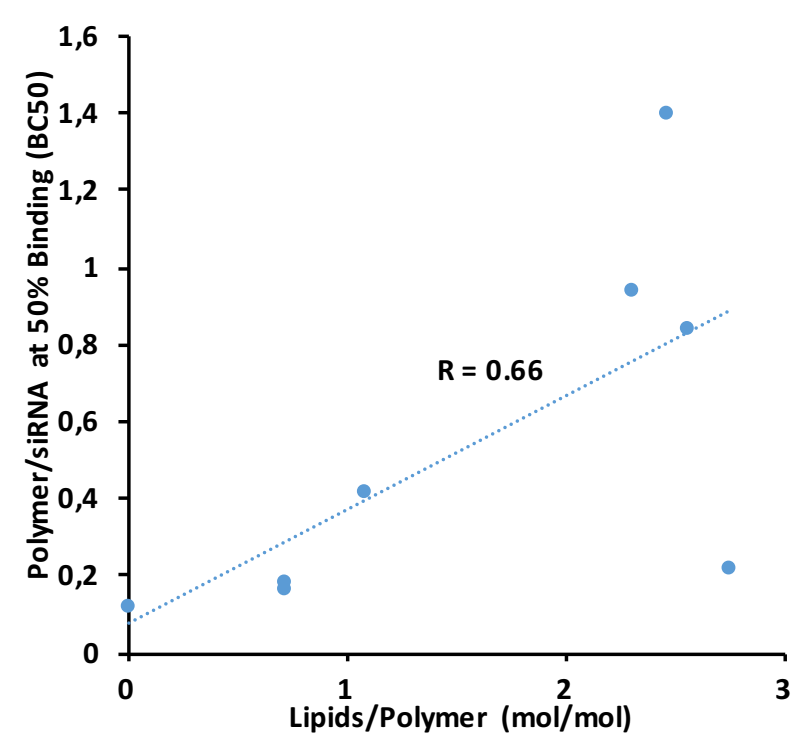

iii

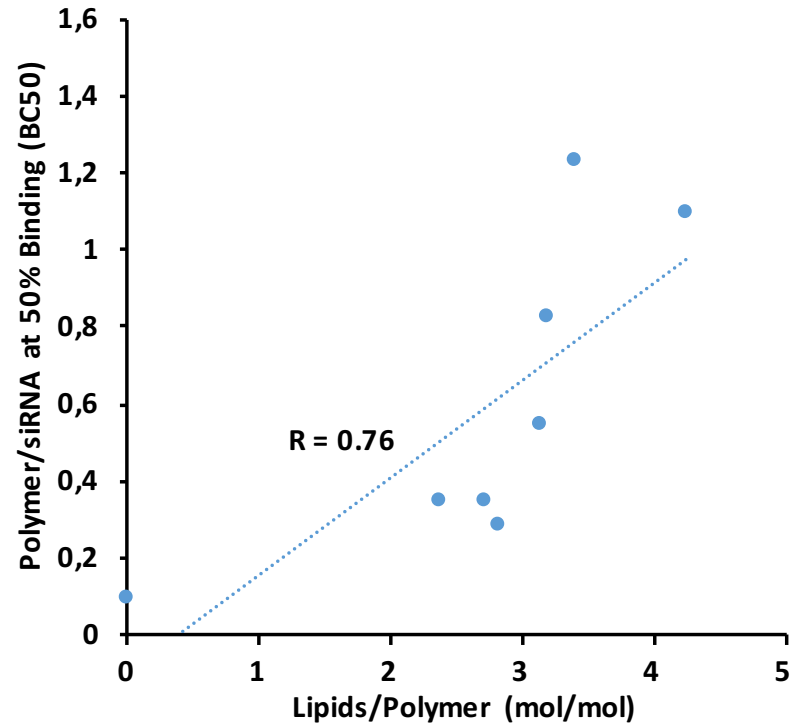

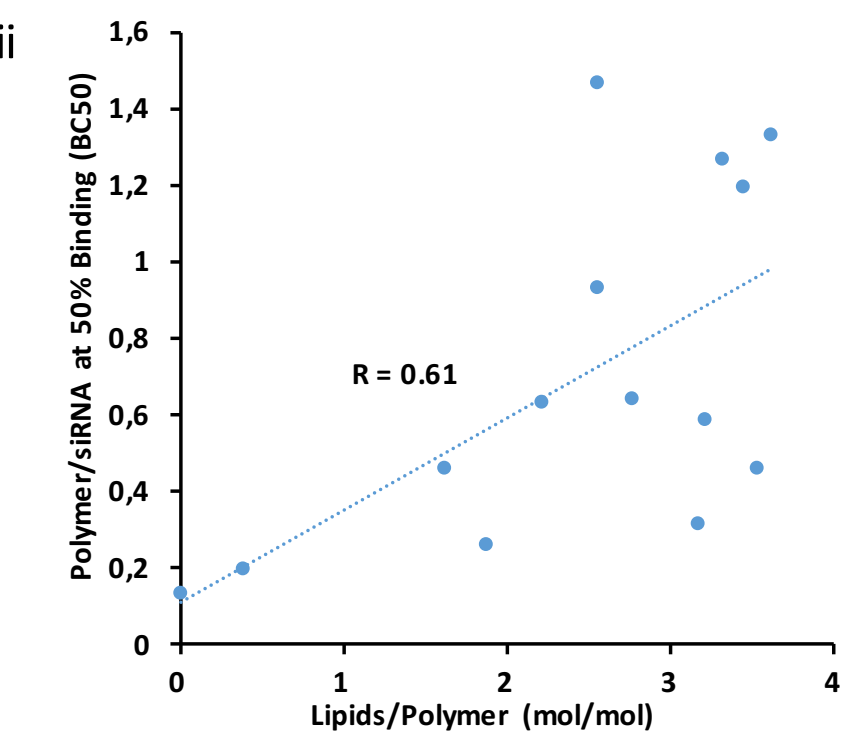

iv

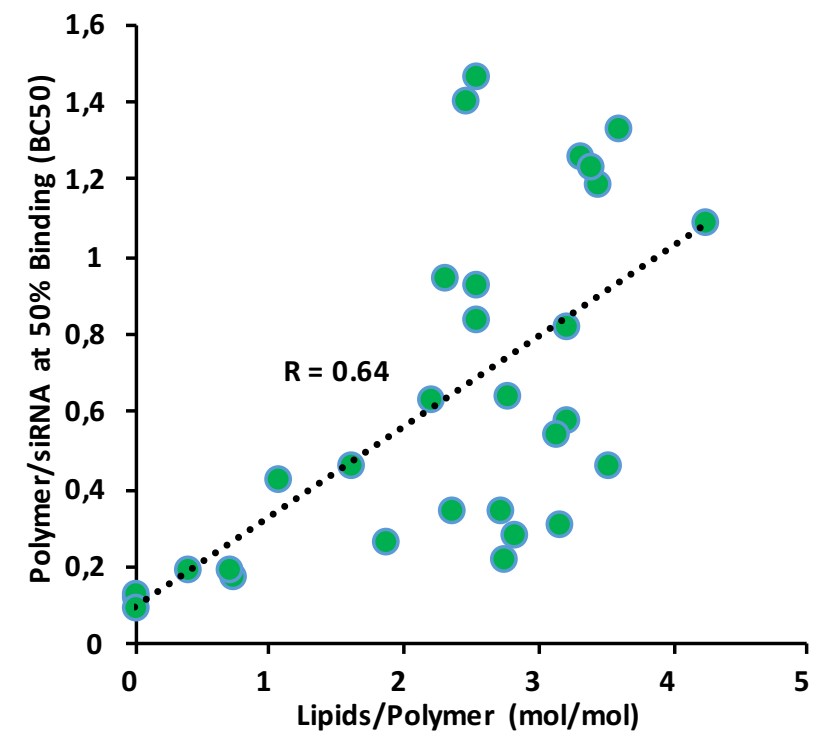


Figure 3

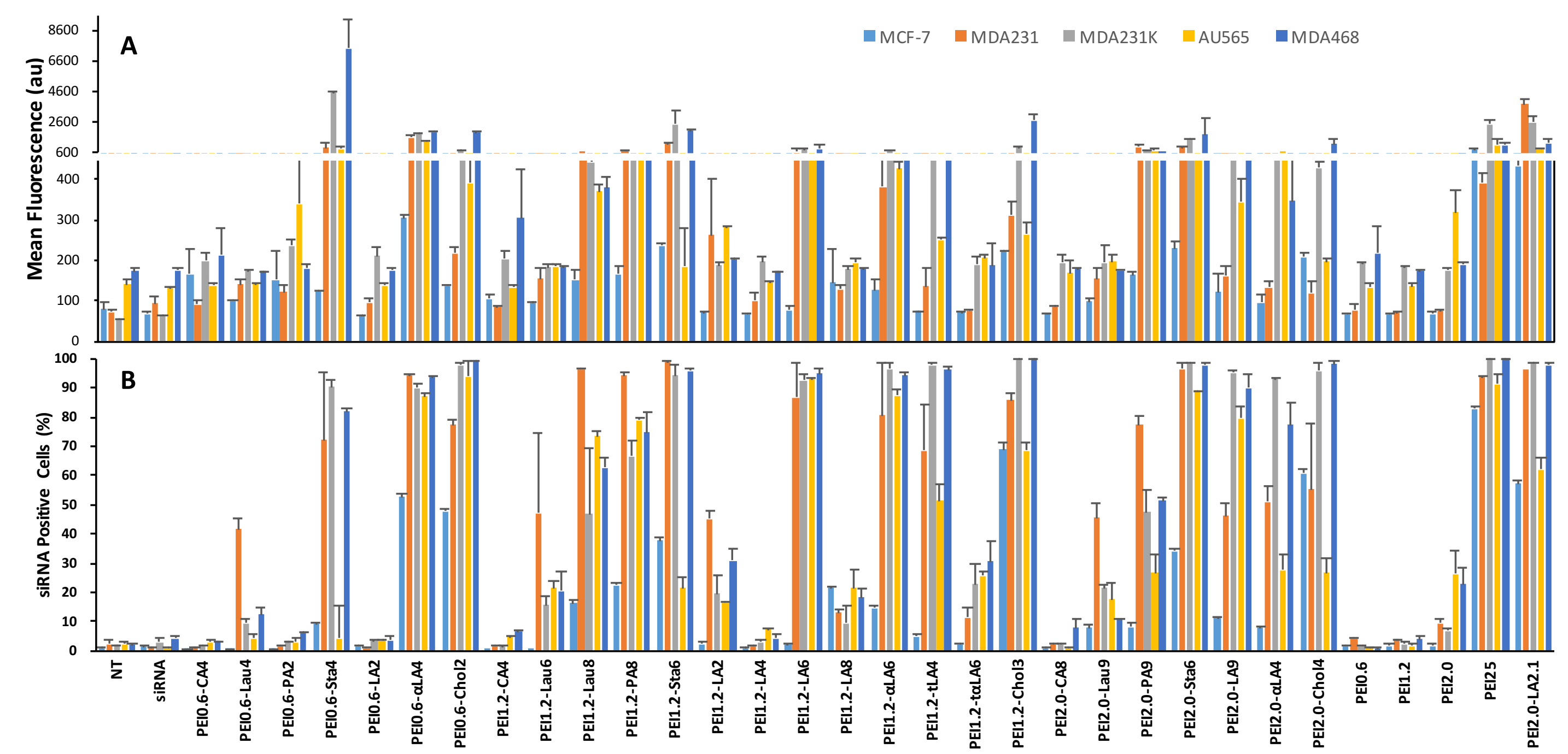


i. Based on \% siRNA-positive cells MCF-7 MDA-231 MDA-231K AU565 MDA-468

PEI0.6

PEI1.2

PEI2.0

PEI0.6-CA4

PEI1.2-CA4

PEI2.0-CA8

PEI0.6-PA2

PE11.2-PA8

PE12.0-PA9

PEI0.6-Sta4

PEI1.2-Sta6

PEI2.0-Sta6

PE10.6-LA2

PEI1.2-LA2

PEl1.2-LA4

PEI1.2-LA6

PEI1.2-LA8

PEI2.0-LA9

PEI0.6- $\alpha$ LA4

PEI1.2- $\alpha$ LA6

PEI2.0- $\alpha$ LA4

PEI0.6-Lau4

PEl1.2-Lau6

PEl1.2-Lau8

PE12.0-Lau9

PEI0.6-Chol

PEI1.2-ChOR

PEI2.0-ChOD

PEI1.2-tLA4

PEI1.2-taLA

PE125

PE12.0-LA2
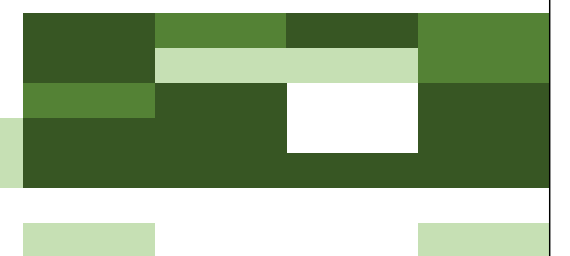

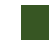
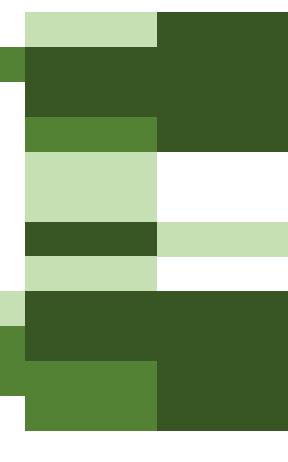

\begin{tabular}{|l|l|}
\hline & Uptake $\leq 25 \%$ \\
\hline & Uptake $\leq 50 \%$ \\
Uptake $\leq 75 \%$ \\
Uptake $>75 \%$
\end{tabular}

ii. Based on Mean Fluorescence

MCF-7 MDA-231 MDA-231K AU565 MDA-468

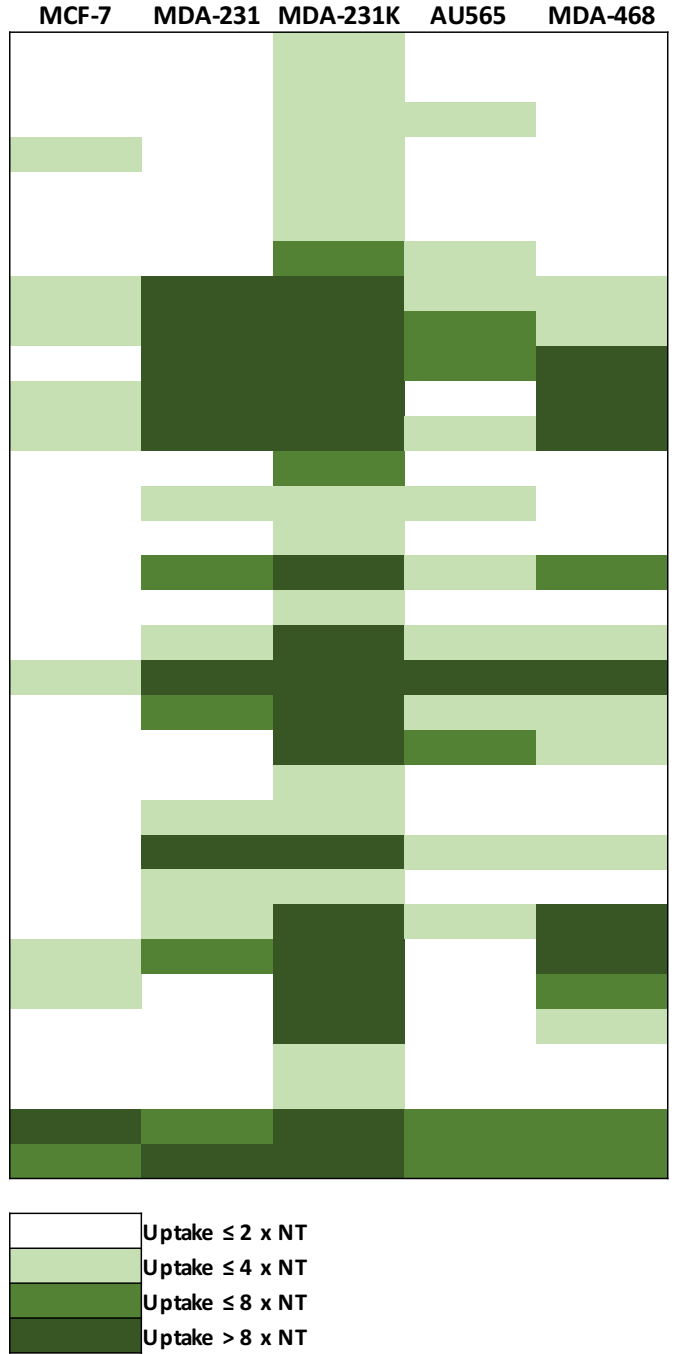


Figure 4

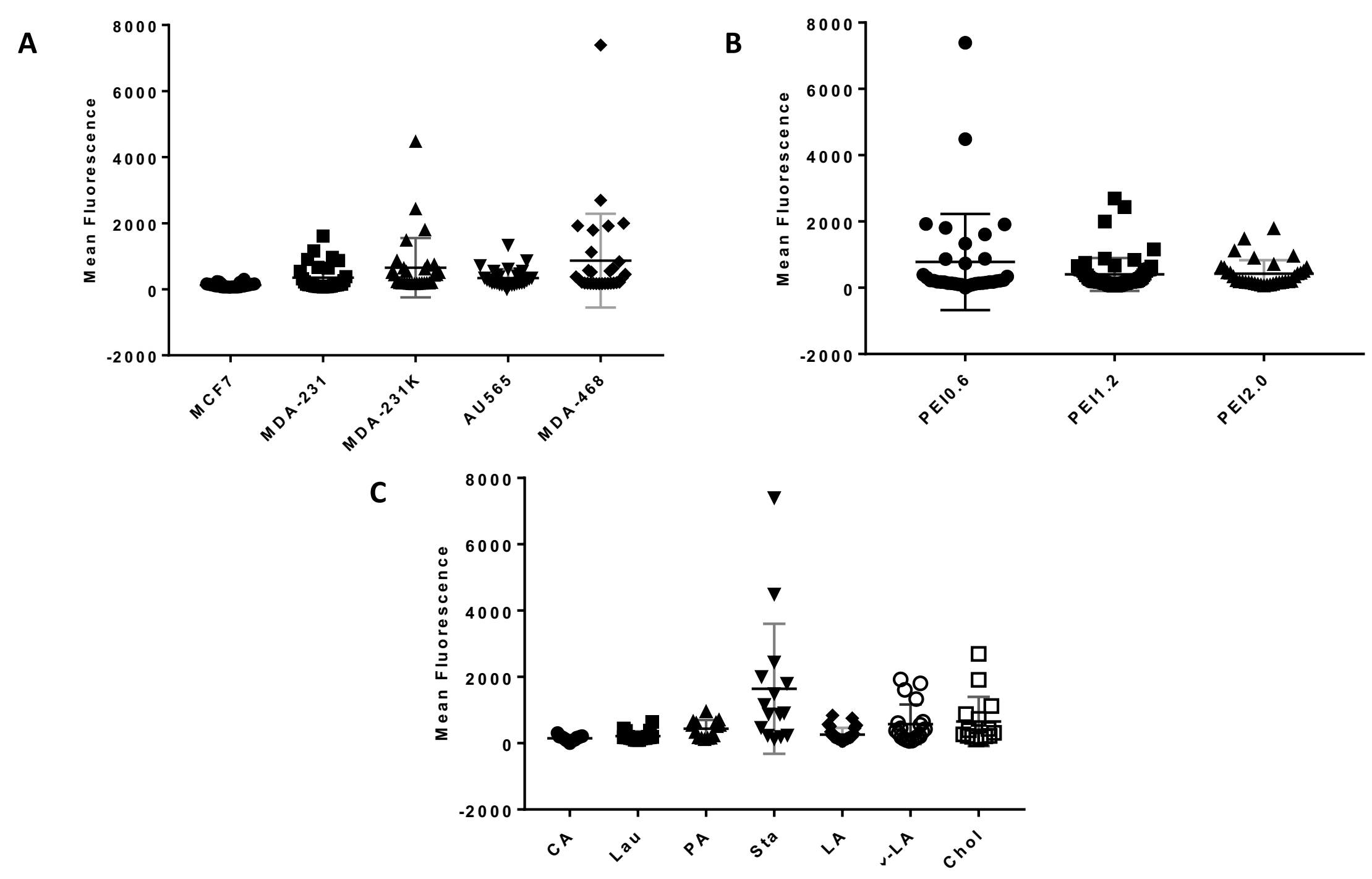




\section{Figure 5}

\section{A}

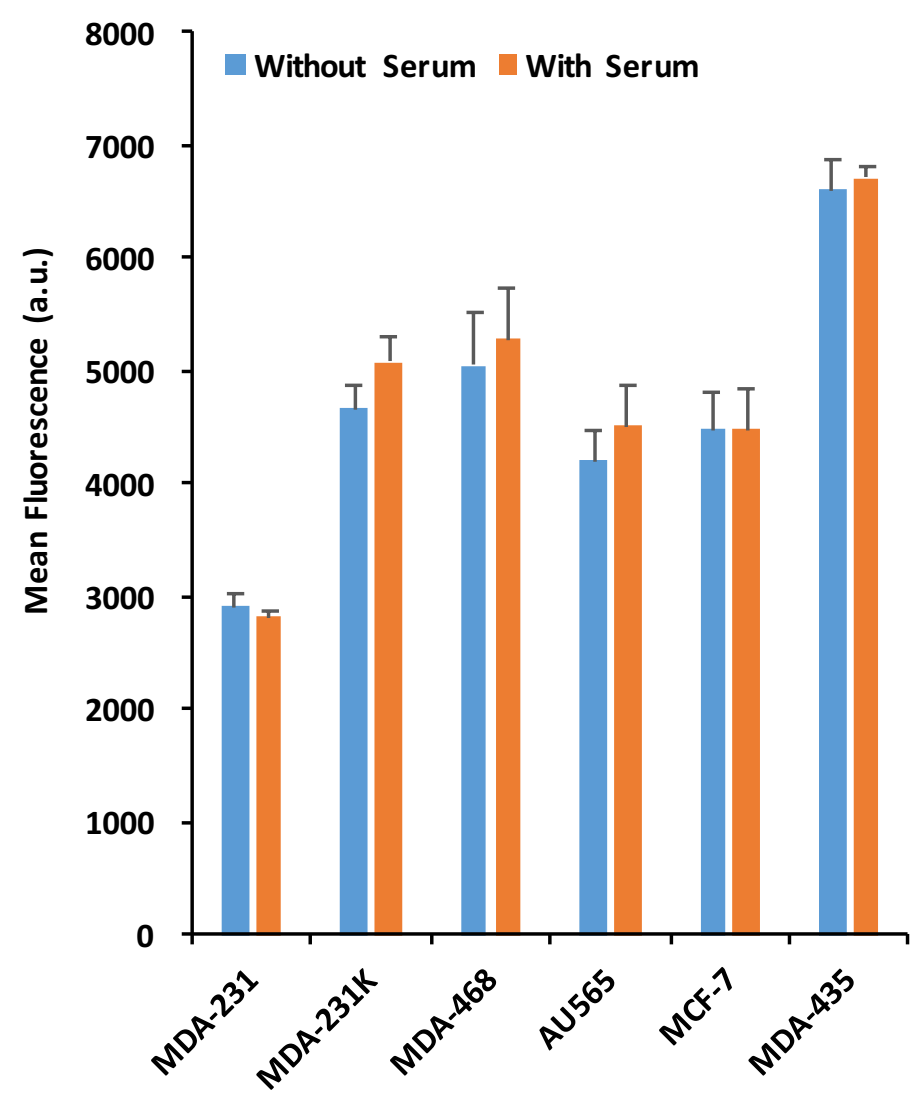

B

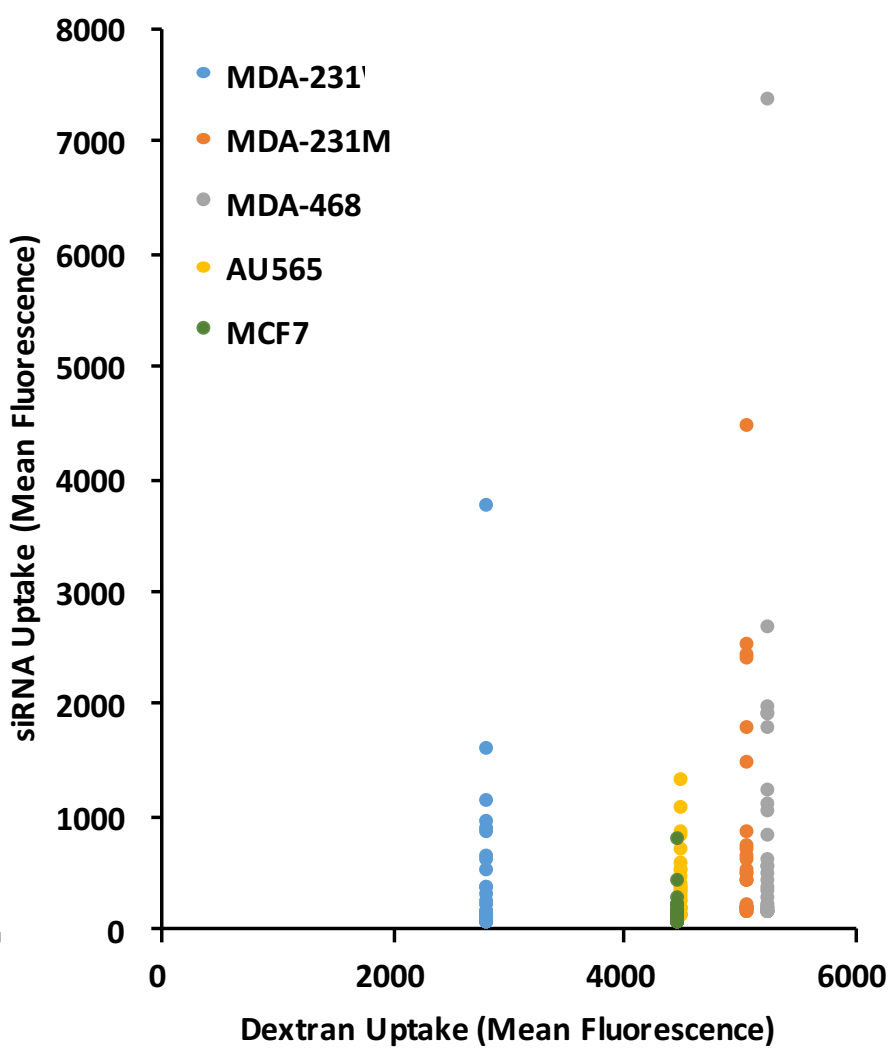

ii. Dextran uptake vs. library (\%-positive)

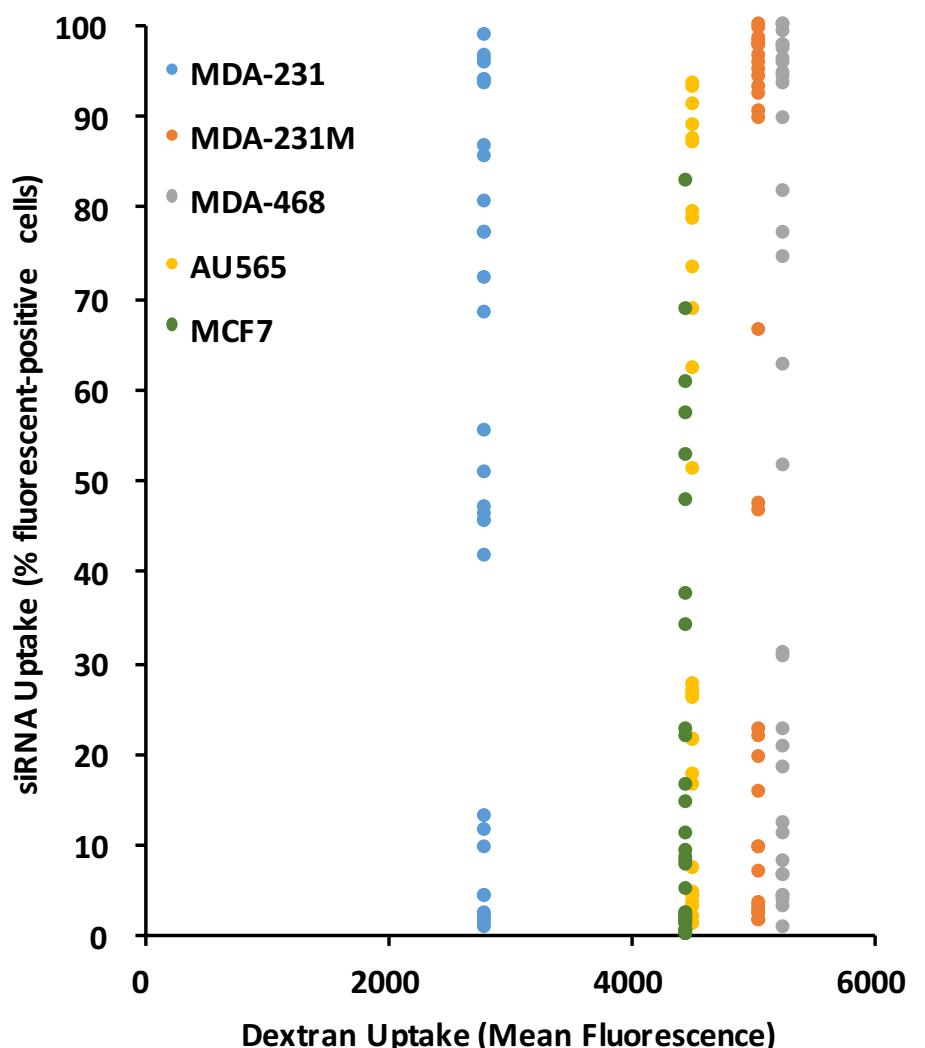


c

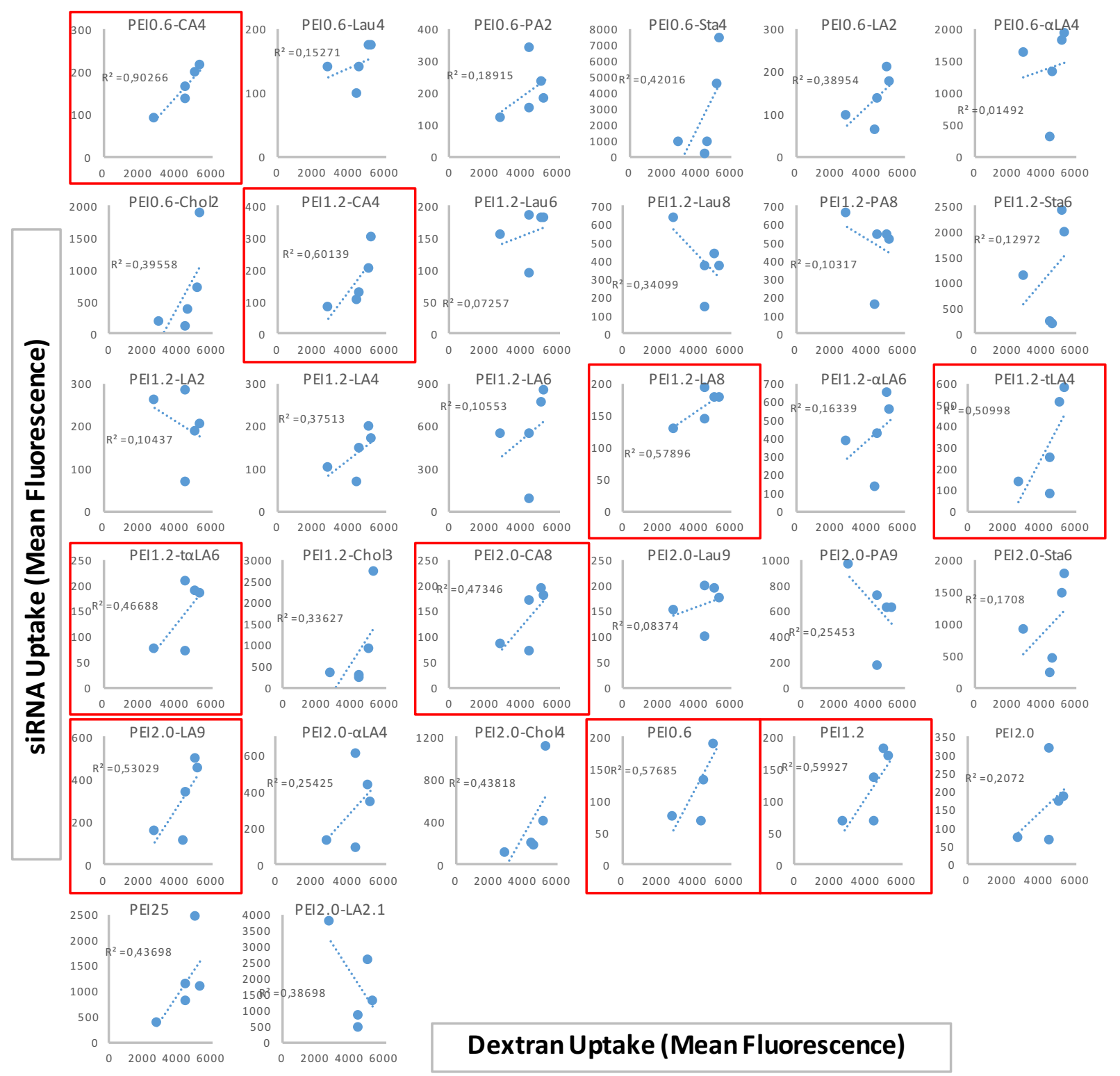


Figure 6A
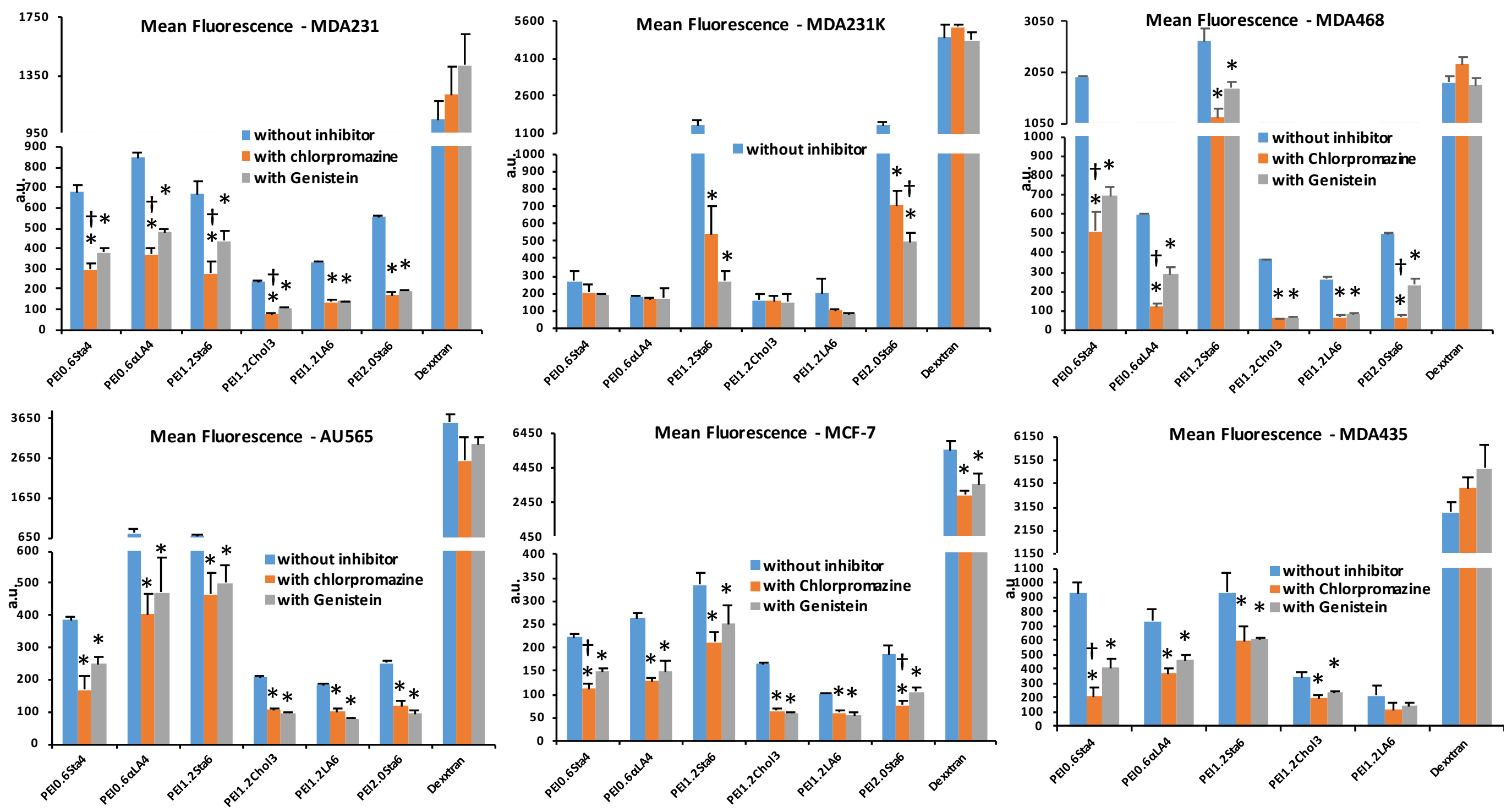


\section{Figure 6B}
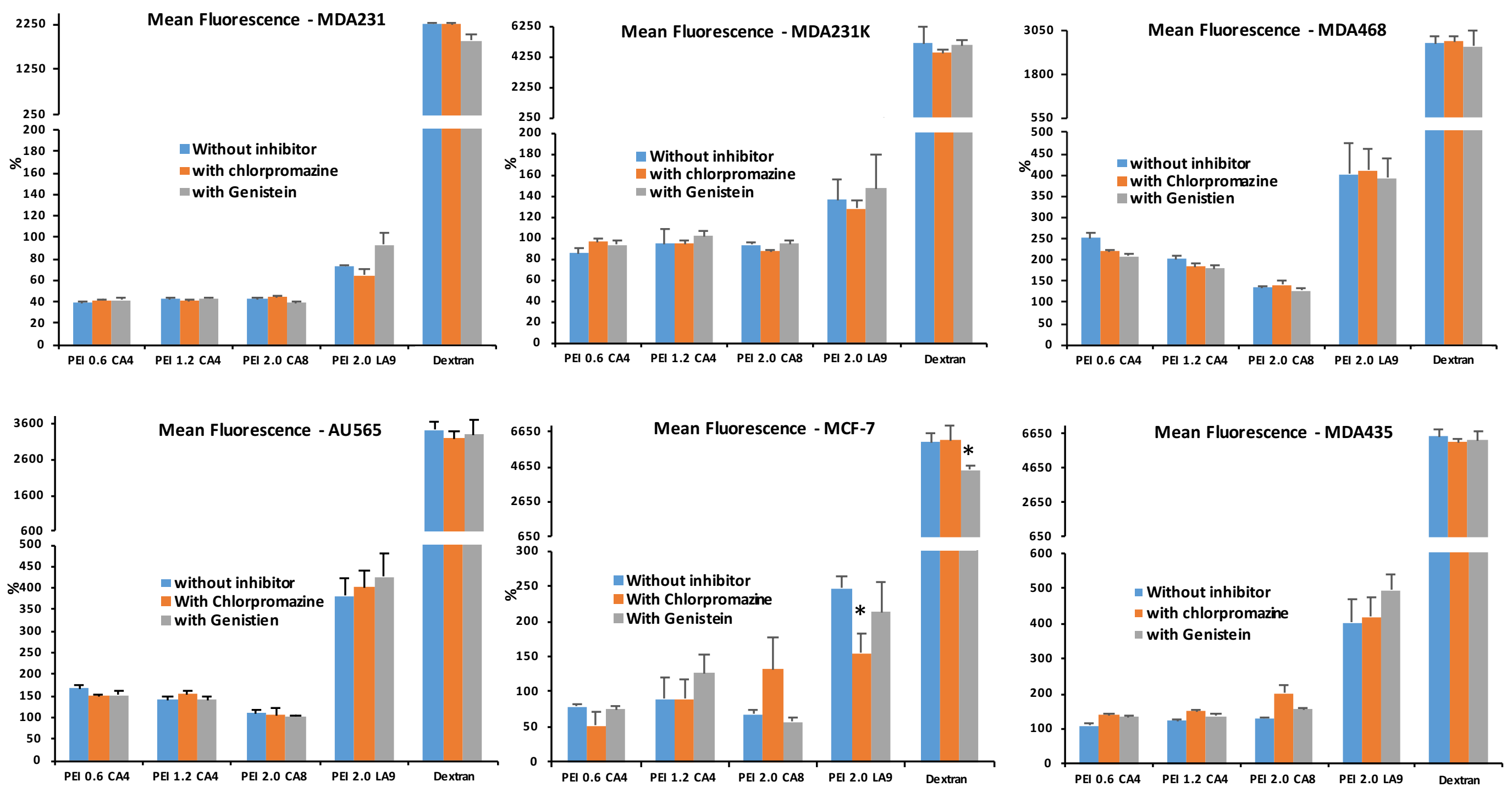
Figure 7A

i
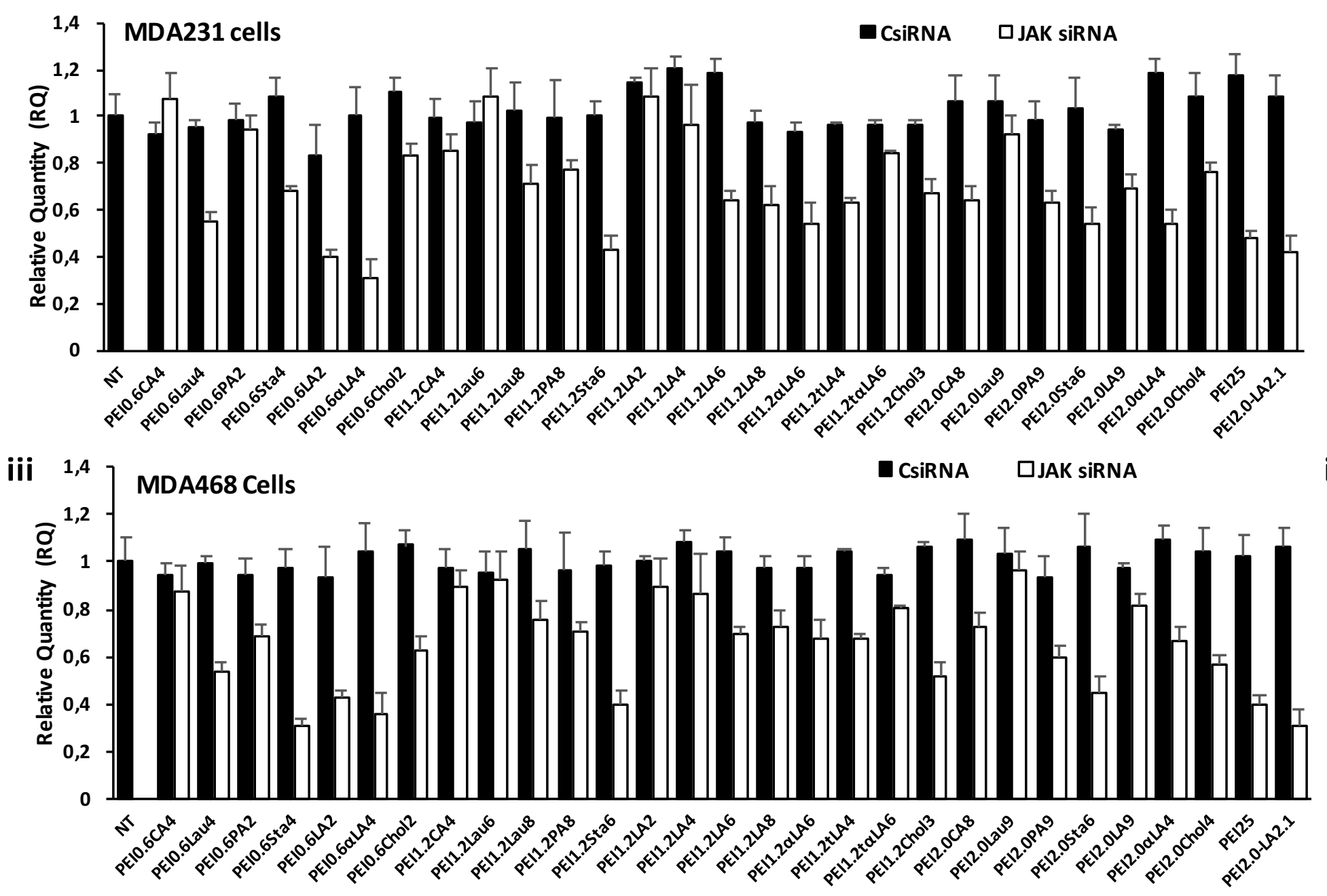

ii
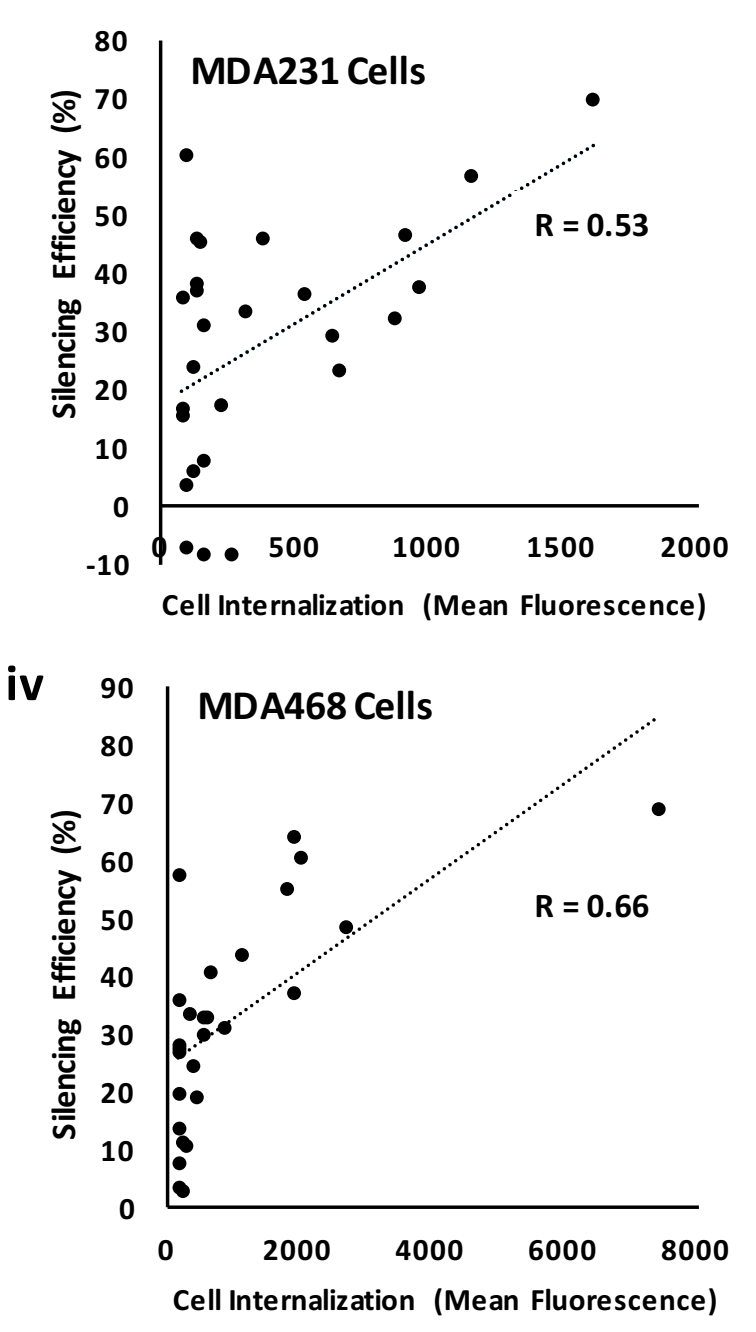


\section{Figure 7B}
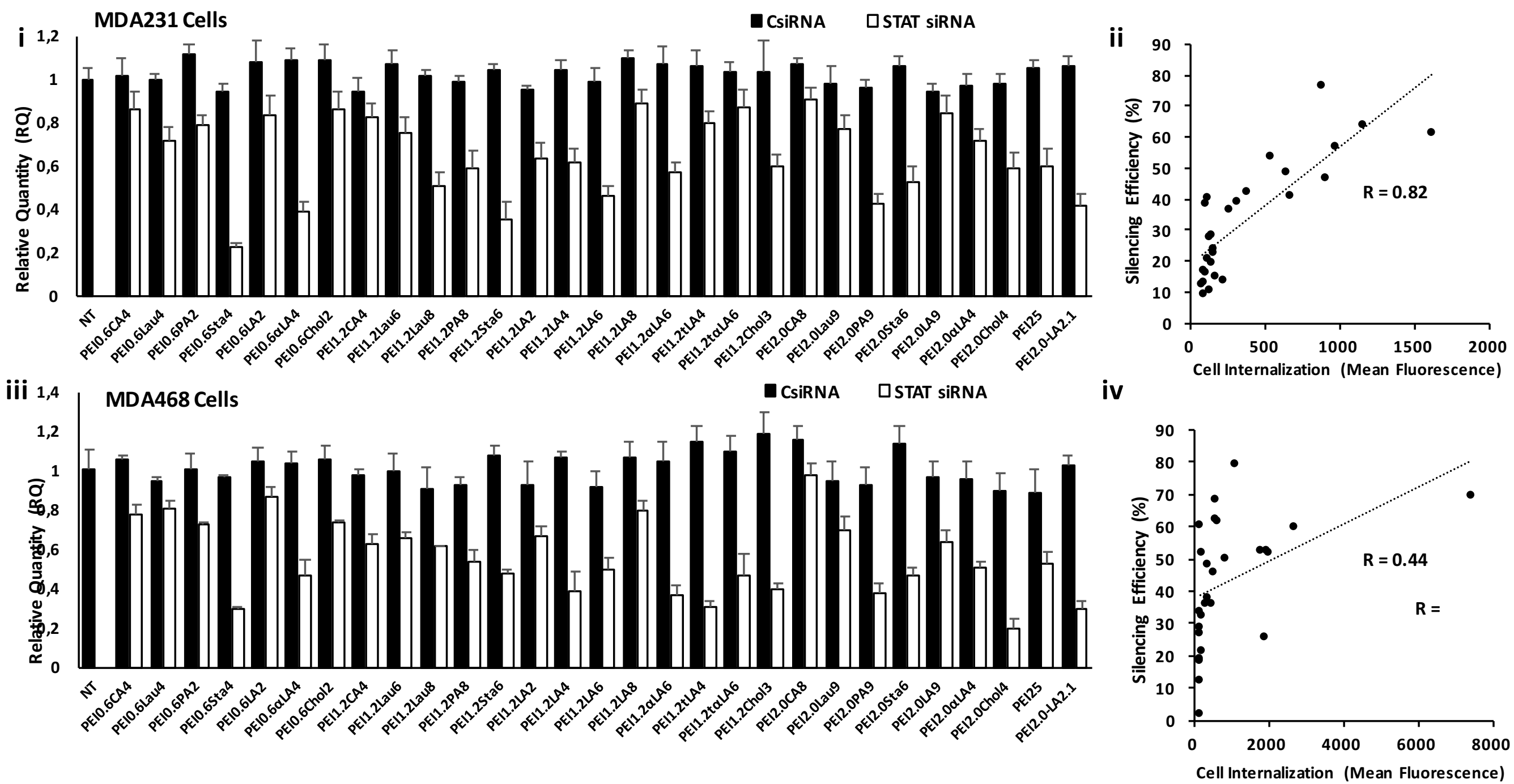
Figure 8
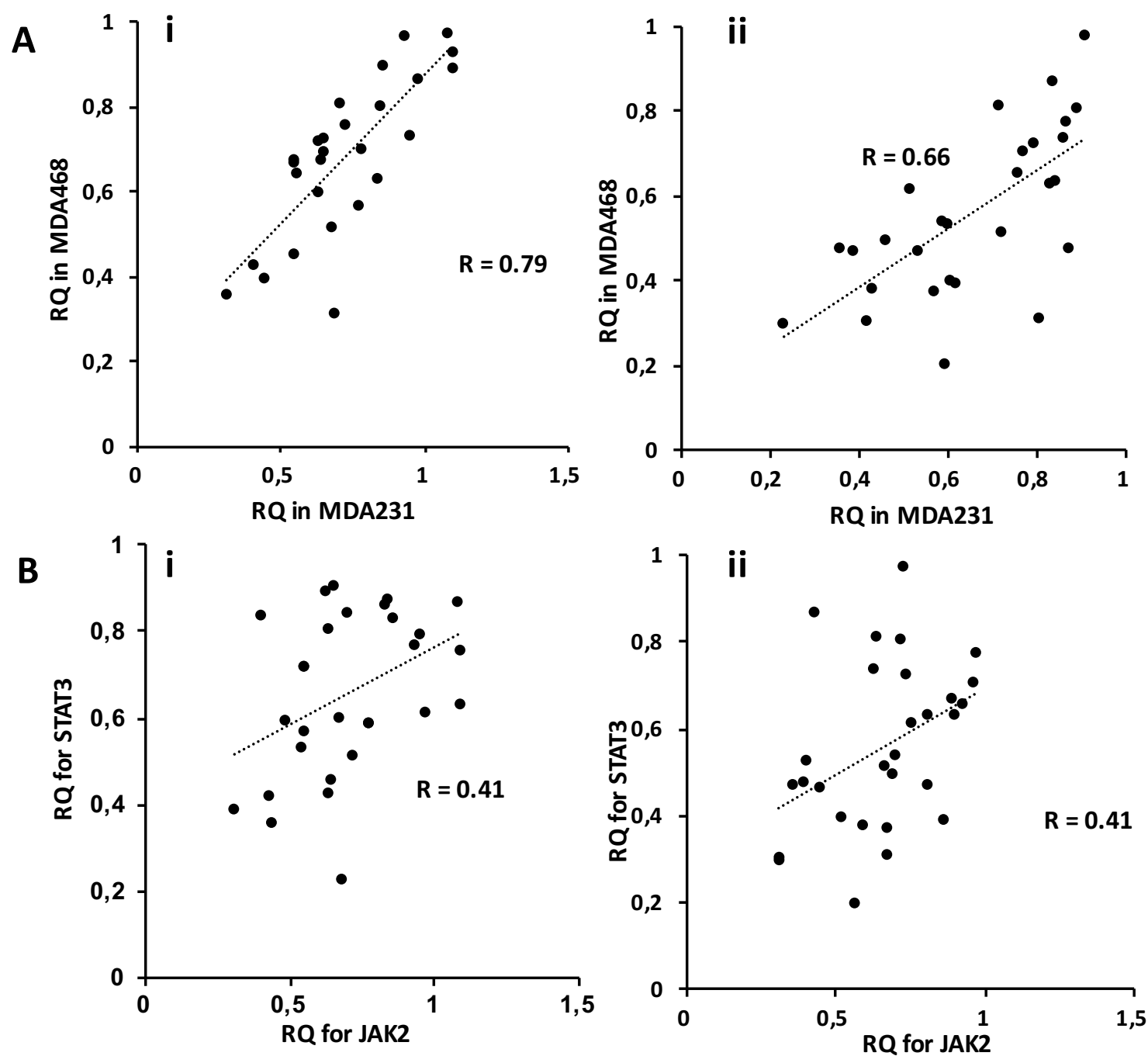


\section{Figure 9}

\section{A}

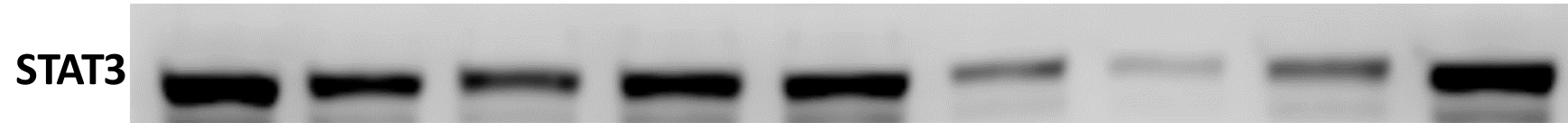

Beta-Actin

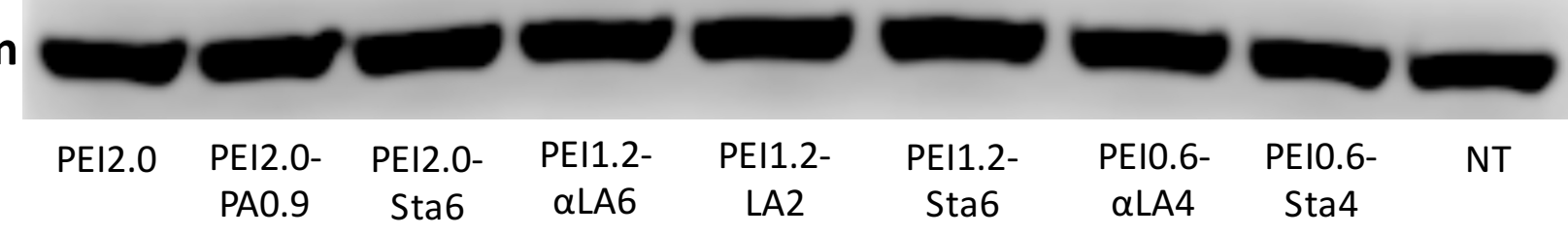

\section{B}

\section{JAK2}

Beta-Actin

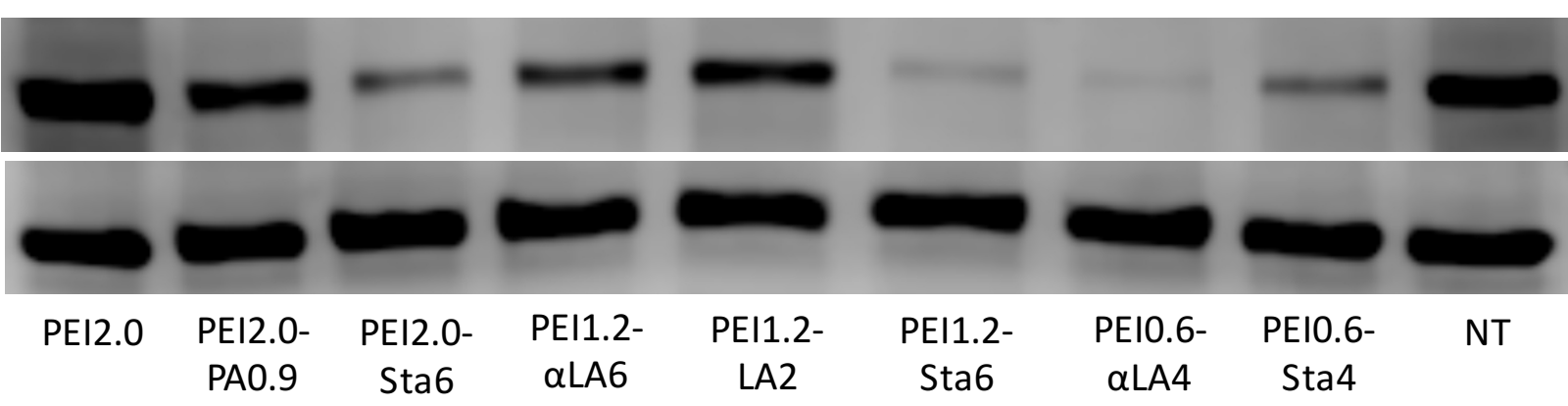

C

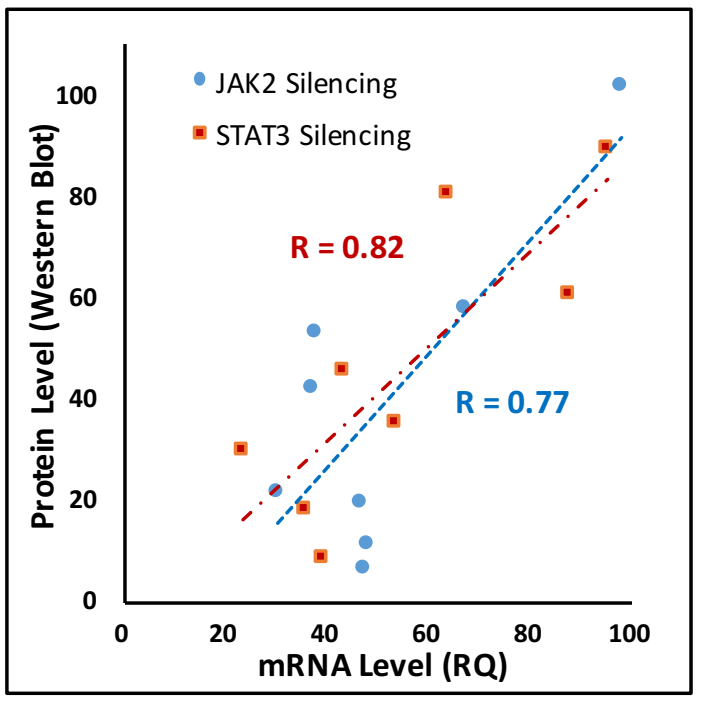

D

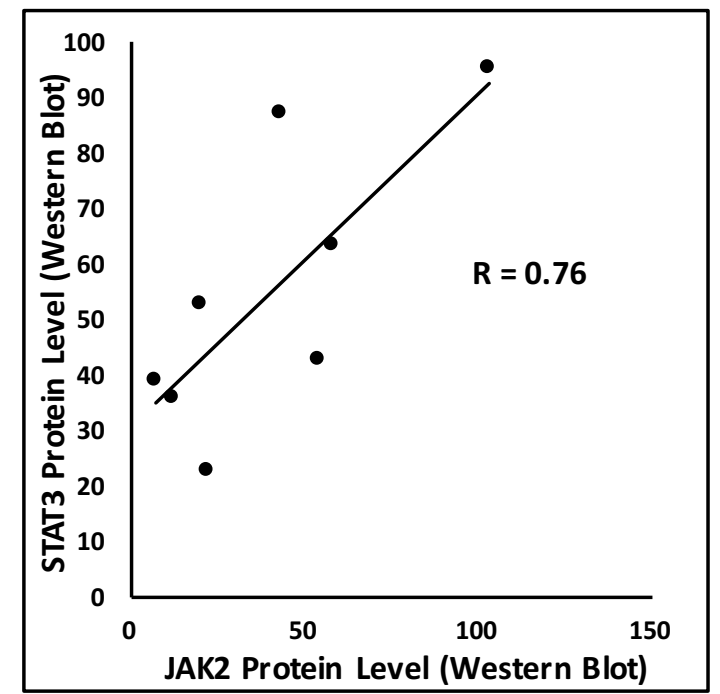


Supplementary Figure 1 - Effect of uptake inhibitors on the siRNA uptake (\% of fluorescent positive cells) with the most effective polymers
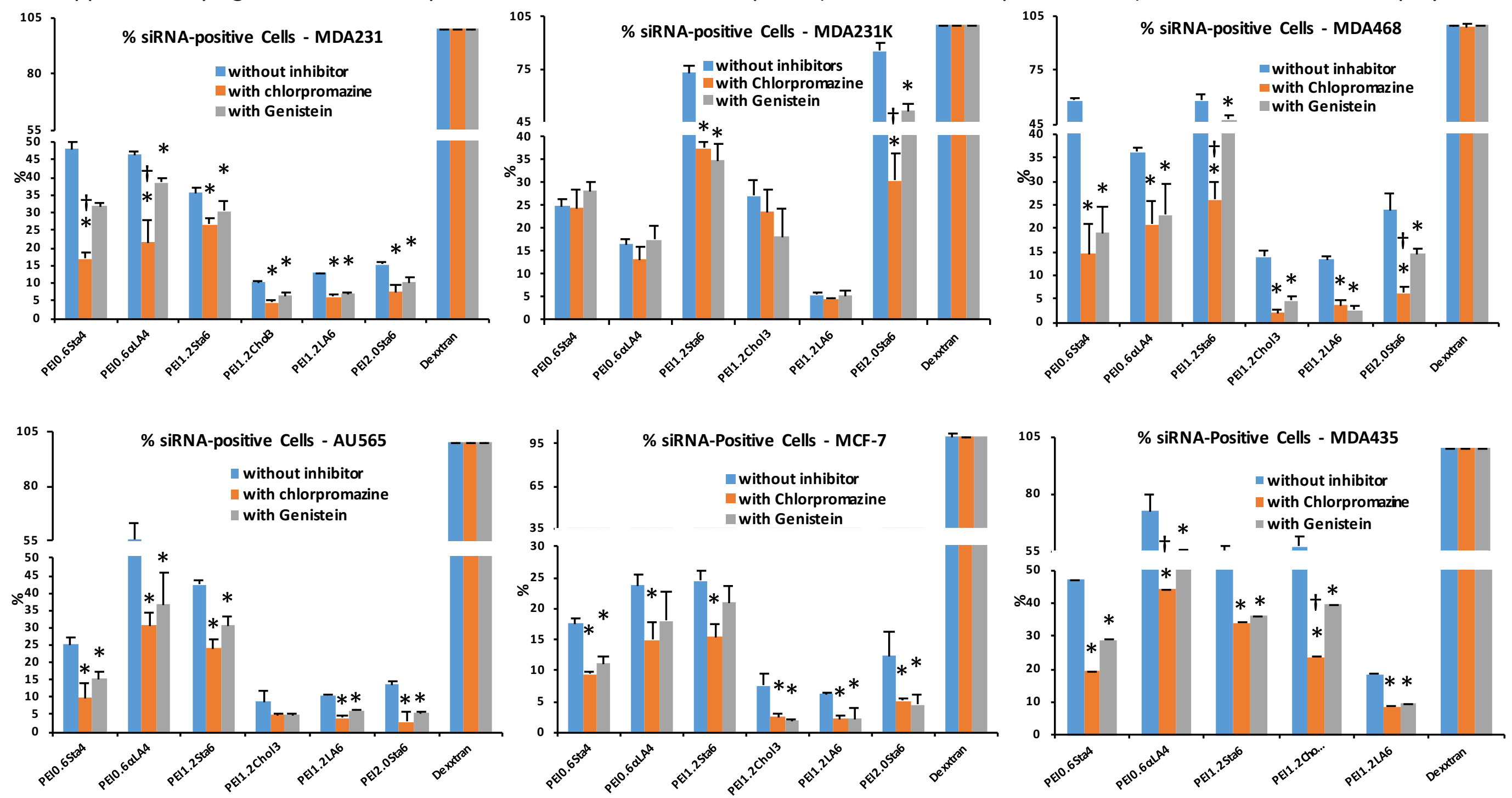
Supplementary Figure 2- Effect of uptake inhibitors on the siRNA uptake (\% of fluorescent positive cells) with the highest correlation with Dextran
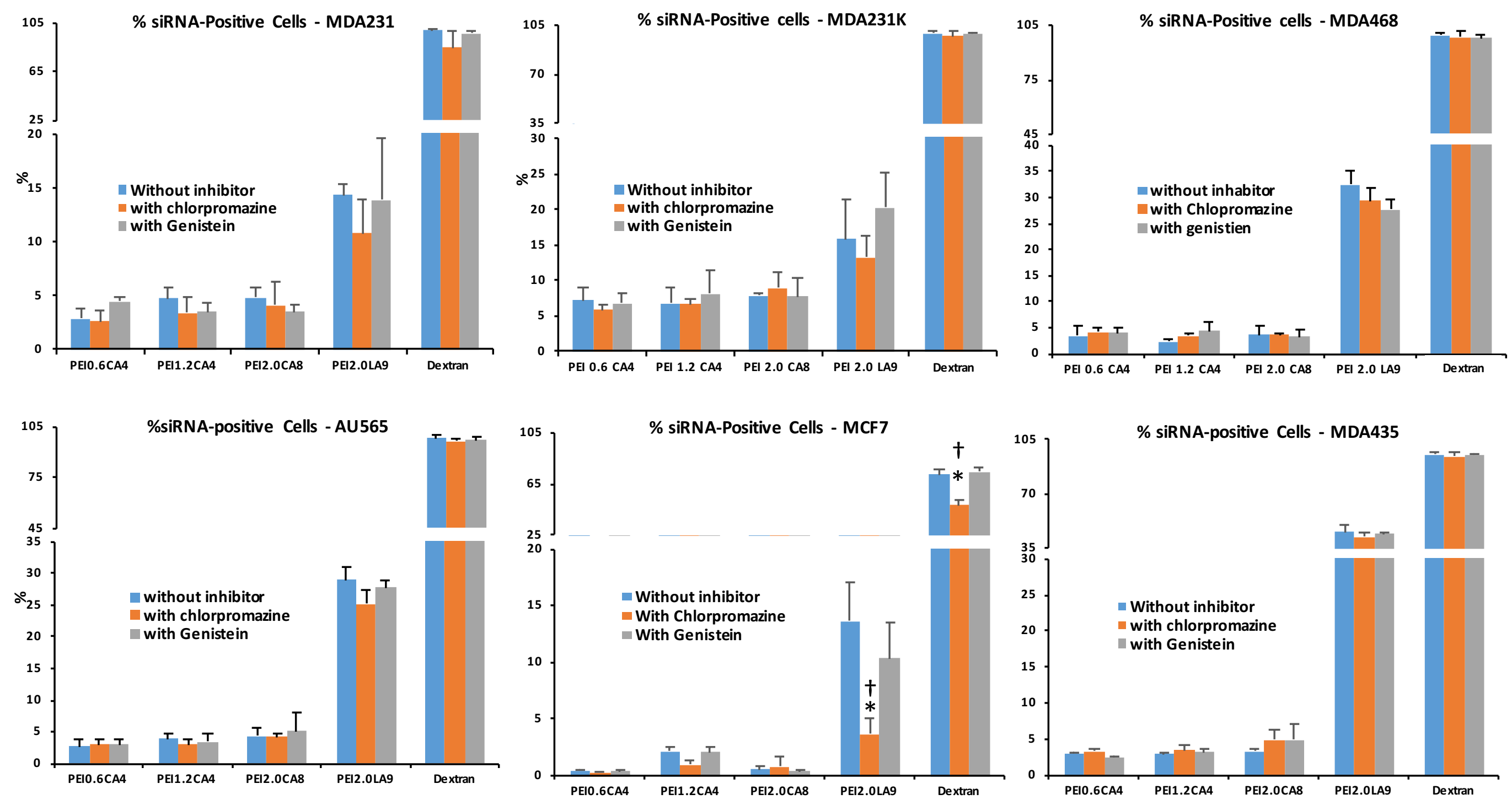